Revista lus et Praxis, Año 24, No 3, 2018, pp. 335 - 378

ISSN 0717 - 2877

Universidad de Talca - Facultad de Ciencias Jurídicas y Sociales

La restitución de mayores ganancias en el incumplimiento eficiente:

una respuesta desde el derecho chileno de los contratos

Pamela Prado López

Trabajo recibido el 14 de noviembre de 2016 y aprobado el 26 de septiembre de 2018

\title{
La restitución de mayores ganancias en el incumplimiento eficiente: una respuesta desde el derecho chileno de los contratos
}

THE RESTITUTION OF HIGHER EARNINGS IN THE EFFICIENT BREACH OF CONTRACT: AN ANSWER FROM THE CHILEAN LAW OF CONTRACTS

Pamela Prado López

RESUMEN

En este trabajo analizaremos los alcances del denominado incumplimiento eficiente, con el fin de determinar si en estos casos es factible que de conformidad al derecho chileno el acreedor obtenga la restitución de las ganancias experimentadas por el deudor; o si, por el contrario, el acreedor sólo puede ejercer los derechos o remedios que la ley le confiere derivados de tal incumplimiento.

ABSTRACT

In this paper, we discuss the scope of so-called efficient breach, in order to determine whether it is feasible that under Chilean law the creditor to obtain restitution of profits experienced by the debtor in these cases, or whether, on the contrary, creditor may only exercise the rights or remedies that the law gives arising from breach.

PalABRAs Clave

Incumplimiento eficiente, restitución de ganancias, acción de rebaja de precio, resolución de contrato

KEY WORDS

Efficient breach, restitution of benefits, action price reduction, termination

\section{Introducción: sobre las dificultades y objetivos de este trabajo}

La figura del incumplimiento eficiente refiere, en forma preliminar, a aquellos casos en que una parte es tentada a incumplir el contrato que ha celebrado, porque el beneficio que obtendrá por tal incumplimiento excede al beneficio derivado del cumplimiento. De manera que si la utilidad del incumplimiento del contrato es superior a aquella que la parte espera obtener con su ejecución, y si, además, los daños experimentados por la contraparte son limitados a la pérdida del beneficio esperado, habrá un incentivo a incumplir ${ }^{1}$. Y es que, como

\footnotetext{
* Abogado, Doctora en Derecho Universidad de Chile, Académica Universidad de Valparaíso, Valparaíso, Chile. pamela.prado@uv.cl.

Este trabajo se enmarca en el Proyecto de investigación Fondecyt "Iniciación" № 11140155.

${ }^{1}$ LIAO (2015), p. 47.
} 
señala Posner, el hecho de que el contratante no ejecute la convención "podría indicar que hay otra transacción que aumenta el valor en mayor medida que la ejecución de una venta contractualmente convenida; en tal caso, queremos alentar el incumplimiento"2.

Pues bien, el aspecto que nos interesa abordar en estas líneas, dice relación con el destino de las mayores ganancias o lucros obtenidos por el deudor debido a su incumplimiento eficiente, pues surge el cuestionamiento en orden a si dichas ganancias permanecen en el patrimonio de éste, toda vez que el interés del acreedor se puede satisfacer a través de los demás derechos que el ordenamiento jurídico le reconoce -por ejemplo, mediante la pretensión indemnizatoria-, o si, por el contrario, el deudor ha de restituir al acreedor aquellos mayores lucros. Nos interesa, especialmente, observar aquellas situaciones en que el acreedor ha padecido daños de menor cuantía a los provechos obtenidos por el deudor, o bien, no ha padecido daño alguno.

Introducirnos en ciertos aspectos del incumplimiento eficiente, puede resultar complejo por razones de variada índole. En primer término, porque nos situamos en un escenario que puede ser difícil de abordar para quien no dedica sus esfuerzos al ámbito del análisis económico del derecho³ ${ }^{3}$ que es el ambiente en que suele enmarcarse el estudio de esta figura; sin embargo, hacemos la precisión de que recurrimos a él únicamente con la finalidad de aislar como objeto de estudio a un conjunto de casos que, desde esa concepción del derecho, pueden calificarse como tales. Por consiguiente, este no es un trabajo de Law and Economics ${ }^{4}$, ni pretende serlo, especialmente si se consideran las múltiples críticas que se han formulado a este enfoque del fenómeno jurídico,

\footnotetext{
2 Posner (2007), p. 219.

${ }^{3}$ Que, como se sabe, "estudia el impacto de la ley lato sensu sobre los mercados, vale decir, sobre las decisiones de propuesta y ejecución de contratos o negocios en general de los sujetos (en particular, empresas). Y de forma más restringida y como aplicación particular, sobre la expresión de la oferta y demanda del objeto de tales contratos y negocios $-y$ por tanto, sobre sus precios y cantidades intercambiadas-". IBAÑEz (2011), pp. 24 y s.

${ }^{4} \mathrm{Y}$ es que hay que tener presente que ya existe gran dificultad a la hora de clarificar qué significa situarse en la esfera del análisis económico del derecho, pues no obstante hay un punto de partida que es asumir que es indispensable reconocer la contribución que ha llevado a cabo la economía en la comprensión de las relaciones sociales y tenerlas presente en el estudio del derecho, se dice que bajo esta denominación cabe tanto un enfoque descriptivo, como normativo, empero, en ambas concepciones el fin último es superar las deficiencias de la dogmática jurídica a la hora de aplicar el derecho. González (1994), pp. 929 y s. De ahí, que nuestro enfoque es distinto de aquel que se lee en un reciente trabajo de Felipe Jiménez, que evalúa desde las concepciones del Análisis Económico del Derecho al incumplimiento eficiente, con el fin de criticar la justificación del mismo y de la indemnización compensatoria como remedio más adecuado, negando, así, una visión de los remedios desde esta óptica. JiménEZ (2017), pp. 127 y s.
} 
sobre todo en el derecho continental ${ }^{5}$, reconociendo, empero, su aporte desde la metodología del derecho ${ }^{6}$. El segundo orden de dificultades, es que para intentar dar respuesta a la interrogante planteada nos debemos situar en una zona en que pueden confluir dos enormes ámbitos del derecho patrimonial: el incumplimiento contractual y el derecho del enriquecimiento injustificado. $Y$ finalmente, debido a que la temática del incumplimiento eficiente ha sido especialmente abordada por estudiosos del derecho anglosajón, por lo que podría cuestionarse la pertinencia del debate en nuestro sistema jurídico. Sin embargo, como se ha señalado, se recurre a la figura del incumplimiento eficiente para separar a un grupo de casos sobre el cual pondremos atención. Por lo demás, hay que reconocer que la reacción de los ordenamientos jurídicos pertenecientes al common law ante un caso de incumplimiento contractual, no es diametralmente diversa de aquellos que conforman el derecho continental' ${ }^{7}$.

Finalmente, debemos aclarar que este es un ensayo que se aborda desde la dogmática del derecho y de lege lata.

\section{Delimitando el incumplimiento eficiente}

Nos situamos, entonces, en aquel incumplimiento contractual motivado porque las ganancias que el deudor pretende obtener del mismo, son superiores a aquellas que espera de la observancia de la convención ${ }^{8}$. Para arribar a ese resultado, se contrastan esas ganancias, con el monto o valor de los potenciales daños que el deudor debiera indemnizar al acreedor. Por consiguiente, no todo

\footnotetext{
${ }^{5}$ Un buen ejemplo de ello, se visualiza en el reciente trabajo de Martínez Cinca, en que se afirma que el análisis económico del derecho ha sido incapaz de proporcionar una teoría general del derecho, en particular, a la hora de "elaborar una teoría general del Derecho en el sentido definido por Dworkin. En efecto, uno de sus mayores obstáculos parece residir en la dificultad para elaborar una teoría coherente y plausible de la adjudicación jurídica (o de las decisiones judiciales) a punto tal que esa dificultad ya no parece proceder del estado embrionario en que la teoría se hallaría -y por consiguiente el logro de su madurez epistemológica tampoco sería una cuestión de tiempo, como afirmaba Richard Posner en los setenta y ochenta- sino en las contradicciones que acarrearía la maximización de la riqueza como pauta de asignación de derechos". MARTínez (2014), p. 927.

${ }^{6}$ Así, el análisis económico del derecho desde la metodología supone reconocer que es una herramienta eficaz para el análisis de los resultados económicos de las normas legales, por lo que posibilita adoptar decisiones en la configuración del ordenamiento jurídico; pone en el tapete el cuestionamiento de la eficiencia de la sustitución de las normas legales; potencia la racionalidad estratégica y la capacidad negociadora del agente. IBÁÑ̃z (2011), pp. 67 y s.

${ }^{7}$ Citando a Cooter y Ulen, si bien el cumplimiento específico es el remedio predilecto en los países de tradición continental, y la indemnización de daños lo es en aquellos del derecho anglosajón, en la práctica, la mayoría de los sistemas jurídicos utilizan remedios similares en similares circunstancias. COOTER y Ulen (2016), p. 307.

${ }^{8}$ Markovits y Schwartz (2011), p. 1944.
} 
incumplimiento será eficiente. Es cierto que, muy probablemente, todo o casi todo incumplimiento acarreará al deudor un ahorro de gastos, pues, al menos temporalmente, implicará un aumento de su patrimonio por la vía de la evitación del desembolso económico que supone todo cumplimiento ${ }^{9}$, pero decimos temporalmente, porque en caso que el acreedor ejerza, luego, alguno de los remedios o derechos que la ley le reconoce, el deudor igual deberá finalmente cumplir, resolver y/o indemnizar, todo lo cual le generará un dispendio, directa $\mathrm{o}$ indirectamente.

Sin embargo, a lo que nos abocaremos en este trabajo, es a aquellas situaciones en que el incumplimiento del deudor está motivado precisamente por el beneficio económico que le puede reportar la inobservancia al contrato; específicamente, nos interesan aquellos casos en que el beneficio se origina debido a la celebración de otro u otros contratos con terceros.

Ahora bien, incluso para los estudiosos del Law and Economics, la noción de incumplimiento eficiente es más amplia: no sólo alude a la hipótesis en que el deudor esté tentado de incumplir porque los daños que debería indemnizar al acreedor son inferiores al beneficio que obtenga; ni tampoco se limita al hecho de que los beneficios deriven únicamente de la celebración de otro u otros contratos con terceros. El fundamento de esta noción es el diseño de instrumentos jurídicos frente a dicho incumplimiento que "produzcan resultados eficientes y socialmente deseables, de modo que el sistema jurídico no induzca al derroche de recursos escasos en la sociedad"10. Es por ello, que hay otras circunstancias que los analistas económicos del derecho incorporan en el incumplimiento eficiente ${ }^{11}$, diferenciando entre el incumplimiento eficiente

\footnotetext{
${ }^{9}$ Como lo ha señalado en nuestro derecho el profesor Daniel Peñailillo, constituye enriquecimiento "también la liberación de una obligación o carga a que estaba sometido". Peñallillo (1996), p. 12.

${ }^{10}$ Gómez (2002), p. 37. Así, también habría incumplimiento eficiente en caso que el deudor prefiera no cumplir no sólo porque un tercero valore más la prestación debida al acreedor, sino porque los valores involucrados en el cumplimiento se hayan elevado desde la celebración del contrato por motivos externos, pp. 32 y s.

${ }^{11}$ Como los dos casos citados por Cooter y Ulen. El primero, referido al Departamento de Bomberos de Boston, que hasta 2001 permitía a sus empleados presentar licencia pagada por enfermedad por tiempo ilimitado, lo que derivó que ese mismo año se acumularon un total 6.432 días. El Departamento, entonces, incorporó en los contratos que a contar de 2002, el máximo de días que cada bombero podía estar con licencia por enfermedad sería de 15 días al año; cada día adicional no sería pagado. Ese año, los días de licencia aumentaron a más del doble, esto es, 13.431. Según se sugirió por el profesor Wilkinson-Ryan, la razón del aumento se debió a la formalización en el contrato no sólo del límite de días de licencia por enfermedad, sino la sanción a su incumplimiento. Esa formalización pudo traer aparejada la inobservancia al contrato. El segundo caso que se cita, es el de un estudio realizado a guarderías de niños israelíes. Los padres debían recoger a sus niños a las 4 PM, a más tardar. Como ello no se cumplía, las guarderías debían invertir una mayor cantidad de dinero para pagar a los cuidadores que se quedaban para supervisar a los niños que no eran recogidos a la hora.
} 
que involucra malas noticias y el que supone buenas noticias, este último, es el más usual ${ }^{12}$. El primero, dice relación con aquel incumplimiento que se debe a circunstancias imprevisibles que tornan más costoso el cumplimiento ${ }^{13}$; en tanto que el segundo tipo, esto es, el incumplimiento eficiente por buenas noticias, es el que nos interesa. Así, un caso profusamente citado por los autores, es el siguiente: supongamos que el 1 de enero, se celebra un contrato de compraventa de 100 unidades de un determinado producto, que el vendedor deberá entregar al comprador el 1 de julio, o antes; el valor de cada unidad es de \$10, por lo que el valor total de las unidades asciende a \$1.000. El vendedor espera gastar \$ 8 por la producción, envío y gastos generales de cada unidad. Por su parte, el comprador pretende comercializar estas unidades, vendiéndolas al mercado en la suma de \$18, pues además del gasto de \$10 en que incurre en cada una de ellas, adiciona $\$ 6$ por concepto de costos de producción, reventa y desembolsos. Por tanto, entre vendedor y comprador invierten \$ 14 netos para producir cada unidad, de manera que el superávit de $\$ 4$ es dividido entre ambos, el comprador toma \$2, y al vendedor también le corresponden \$2. Un incumplimiento eficiente por buenas noticias, sería si un tercero se contacta con el vendedor y le ofrece comprar las 100 unidades por \$1.300. En este escenario, el tercero es un competidor del comprador y está dispuesto a pagar más por los bienes, tal vez, porque tiene un nuevo método de producción menos costoso. De manera que si el vendedor tiene la capacidad para producir únicamente 100 unidades, sólo podrá vender al tercero, incumpliendo a su primer comprador ${ }^{14-15}$.

Para evitarlo, se introdujo en los contratos en forma expresa el pago de una multa a cada padre que se retrasara; sin embargo, el retraso de los padres se incrementó, lo que llevó a los especialistas a teorizar que era igualmente más eficiente recoger tarde a los niños. Sobre ambos casos, además, se observa que el mismo profesor Wilkinson-Ryan es de la idea que cuando las obligaciones son de naturaleza informal, hay un mayor incentivo a ser cumplidas, acorde a las normas compartidas por la comunidad, pero cuando las sanciones se especifican ya en un contrato, el comportamiento de las personas se vuelve más estratégico. COOTER y Ulen (2016), pp. 324 y s.

${ }^{12}$ KLASS (2015), p. 364.

13 Gaviria (2015), pp. 39 y s.; Jiménez (2017), p. 107.

14 KLASS (2015), p. 365.

${ }^{15}$ Similar al caso citado por Cooter y Ulen: se contrata entre A y B, para que A construya un determinado aparato personalizado para B; la entrega del mismo debería realizarse en septiembre, sin embargo, en agosto $\mathrm{A}$ se da cuenta de que los costos son mayores que los que había previsto, y, por cierto, mayores que los cobrados a B. En el ínterin, C le ofrece pagar una cantidad superior por el mismo aparato. Se señala por estos autores, que entregar el aparato a B sería ineficiente, por lo que A podría o incumplir el contrato con B y pagar los daños, o bien, renegociar el contrato con B y liberarse del contrato, normalmente entregando una cantidad superior al valor por el que se había contratado. COOTER y ULEN (2016), p. 325. 
Pensemos, así, en una compañía que se dedica a prestar servicios de limpieza mediante el suministro de trabajadores. Pues bien, esta es contratada por otra empresa con quien se obliga a suministrar diez trabajadores, quienes deberán llevar a cabo la limpieza de los recintos en que funciona el acreedor durante la noche. En el intertanto, otra compañía se interesa por iguales servicios y le ofrece un precio mayor, pero atendido que la compañía de limpieza no cuenta con más trabajadores, destina a ella la mitad de los trabajadores que inicialmente debían llevar a cabo sus labores en la primera empresa. No obstante, y aún a costo de la mayor recarga de los trabajadores, se cumple con la limpieza en forma idónea, por lo que aunque hubo incumplimiento que podríamos calificar de imperfecto, al no destinarse los diez trabajadores a que se había comprometido, no hay perjuicios para la primera acreedora.

En otro caso similar, supongamos que una empresa constructora celebra un contrato de arrendamiento de encofrados para sostener un puente en construcción. Los encofrados deben cumplir con determinadas especificaciones técnicas, a fin de que sustenten de forma adecuada al puente mientras culminen las obras. Pero los encofrados que se envían se encuentran en mal estado o no cumplen con las especificaciones requeridas, e igual se utilizan hasta el fin de la obra y nada ocurre. La razón del incumplimiento de la empresa dueña de los encofrados, es que los que estaban en buen estado se enviaron a una nueva obra, a cuyos dueños se cobró un valor muy superior por concepto de renta.

Ahora bien, el hecho de que nos situemos en una zona que hace dialogar al incumplimiento del contrato y sus consecuencias, con el derecho del enriquecimiento sin causa, puede generar algunas confusiones entre los casos que son de nuestro interés, con otras situaciones que pueden estár vinculadas con éstas, pero que son diversas.

Por ejemplo, no debemos confundirlo con la restitución de los mayores gastos que le ha ocasionado el cumplimiento del contrato al deudor. Acá, éste ha cumplido, pero a un mayor costo que el presupuestado al tiempo de celebrar la convención ${ }^{16}$. Este tipo de conflictos se ha presentado en nuestro país

\footnotetext{
${ }^{16}$ En nuestro país se han planteado, de tanto en tanto, este tipo de demandas, fundadas, entre otros argumentos, en el empobrecimiento injustificado experimentado por el deudor, como en un caso en que el demandante ejerció acción de indemnización de perjuicios pretendiendo que se le resarciera una cantidad cercana a los novecientos veintiún millones de pesos. La demanda se fundaba en que la demandante, empresa constructora, se obligó a ejecutar una obra consistente en soluciones sanitarias con viviendas de asentamiento para el Servicio de Vivienda y Urbanismo, por la cual se le pagaría la cantidad de ochocientos cincuenta y un millones de pesos, pero durante la ejecución del contrato el contratista debió afrontar una serie de inconvenientes, entre ellos, los referidos a la calidad del suelo, a las redes de agua potable, a la falta de una serie de autorizaciones administrativas, todo lo cual retrasó la obra impidiendo su entrega definitiva en la fecha acordada y ocasionándole los daños que ella indica. La sentencia de primera instancia acoge la demanda, confirmada luego en segunda
} 
en contratos de construcción a suma alzada, en que es bastante corriente que no obstante se haya pactado el pago de una suma única al contratista, durante la vigencia del contrato éste sufra una serie de contingencias que generan un alza en los costos que se tenían en vista al momento de contratar ${ }^{17}$.

En segundo término, también es preciso separar los casos de incumplimiento eficiente, de aquellos en que el incumplimiento del deudor produce, a la vez, una ganancia al acreedor, conocido como el principio compensatio lucri cum damno ${ }^{18-19}$.

instancia. La Corte Suprema acoge el recurso de casación en el fondo deducido por la demandada, pero sólo para dar lugar a la aplicación de la norma contenida en el art. 90 del D.S. № 236, que establece el pago de una indemnización al contratista en casos como el descrito. Agrega la Corte que normas como estas tienen por finalidad adecuar el equilibrio del contrato. Ciertamente en este caso era factible aplicar una norma expresa como es la indicada, pero es interesante la mención que hace el máximo tribunal en orden a la necesidad de volver a un equilibrio económico entre las partes; empero, nada expresa respecto de la figura del enriquecimiento injustificado -Corte Suprema, rol № 7446/2011, de 15 de julio de 2013-. Un caso similar, fue el planteado por otra empresa constructora que demandó a una municipalidad, fundado en que, no obstante estar ante un contrato de construcción a suma alzada, nuevamente la ejecución del contrato le produjo mayores gastos, los que no fueron pagados por la demandada, pretensión que se canalizó nuevamente mediante una demanda indemnizatoria. En este caso, sin embargo, la demanda fue rechazada debido a que la actora no logró demostrar el incumplimiento de la demandada Corte Suprema, rol № 2708/2011, de 18 de junio de 2013.

17 Sobre el particular, en forma reciente el trabajo de Correa Ferrer y García Mekis. Estos autores señalan que en estos contratos es frecuente que los conflictos se presenten precisamente por el aumento de costos del contrato y la extensión en el plazo de las obras. Los autores concluyen que si bien la regla general es que los tribunales nacionales hacen prevalecer el acuerdo de las partes respecto del precio pactado inicialmente, en algunos casos excepcionales se ha matizado esta posición si el desequilibrio contractual es especialmente grave, empero, los casos que citan los autores son bastante anteriores. CORREA y Ferrer (2016), pp. 53-61. Sobre este punto, también se ha referido Sutherland, aunque con énfasis en el análisis del artículo 2003, regla segunda del CCCh. SutherLand (2014), p. 191.

${ }^{18}$ En nuestro país esta figura ha sido abordada por Sergio Gatica Pacheco, que plantea que un elemento que el tribunal debe tener presente al fijar el monto de la indemnización de perjuicios, son las ventajas que hayan podido derivarse del incumplimiento para el acreedor, las que deben ser compensadas con el monto de los perjuicios que éste demanda, y da como ejemplo el caso en que el vendedor incurre en mora al entregar ciertas mercaderías al comprador, aumentando de valor en el tiempo intermedio; pues bien, el monto de la indemnización que luego el vendedor deberá pagar al comprador será menor, que de no haberse producido dicho aumento. Gatıca (1959), pp. 183 y s.

${ }^{19}$ Un trabajo reciente de Medina Crespo estudia este mecanismo reductor del daño indemnizable en forma bastante amplia, puesto que, a diferencia de Gatica Pacheco, considera todo beneficio que el perjudicado obtenga del hecho dañoso, tanto directa como indirectamente. Medina (2015), p. 53. Díez Picazo es de la misma idea, agregando que "la computación de ventajas parece presentar un carácter lógico", aunque deberían excluirse los lucros que provengan de "títulos diferentes del derecho originado en el hecho dañado en sí mismo considerado como ocurre con los posibles derechos hereditarios en el caso de fallecimiento o con las indemnizaciones que deban percibirse en virtud de un seguro de vida". Díez PICAzo (2011), pp. 342 y s. A la vez, el artículo VI 6:103 del MCR, la acoge expresamente, al disponer: "(1) Los beneficios que el perjudicado obtenga con motivo de la causación del daño jurídicamente relevante no se tendrán en cuenta salvo que sea justo y razonable hacerlo". 
Una tercera situación que debemos despejar, aunque íntimamente vinculada a las hipótesis que nos interesan, es el daño por intromisión que, en términos más generales, podría dar lugar a la tutela aquiliana del crédito. Y es que si nos hemos situado en casos en que el deudor deja de cumplir porque ello le proporcionará mayores ganancias, ya hemos dicho que una posibilidad es que esas mayores ganancias provengan de un contrato que celebra con un tercero sobre el mismo objeto del contrato primitivo -entendiendo por objeto, desde luego, a una misma cosa o a unos mismos hechos debidos-. De ahí que los casos de incumplimiento eficiente por buenas noticias serían, en buena medida, coincidentes con algunos de daño por intromisión, razón por la cual interesa mirar un poco más de cerca esta figura.

Con todo, la diferencia entre el daño por intromisión y lo que hemos denominado incumplimiento eficiente, es una cuestión de enfoque. Para efectos de este trabajo, el problema del incumplimiento eficiente lo circunscribimos a la relación entre las partes del contrato; en tanto que el daño por intromisión supone preguntarse si el ordenamiento jurídico prevé una acción resarcitoria en favor del acreedor al que no se le cumple, en contra del tercero que ha impedido dicho cumplimiento. Igualmente, conviene precisar que las situaciones que se han calificado como daño por intromisión no son únicamente los referidos a la celebración de un contrato incompatible con un contrato anterior, sino que también comprende otro tipo de casos en que el comportamiento de un tercero puede impedir que el contrato se cumpla.

En nuestro país se ha ocupado del daño por intromisión el profesor Bustamante Salazar, quien citando doctrina foránea, se sitúa justamente en el caso en que un deudor incumple su contrato por haber celebrado y luego cumplido, un contrato acordado con un tercero, incompatible con el prime$\mathrm{rO}^{20}$. Si bien el autor resalta que sería posible sustentar en nuestro derecho la improcedencia de una acción de responsabilidad extracontractual en contra del tercero, debido a que los derechos de crédito sólo han de ser respetados entre las partes del acuerdo, agrega que también están en juego los derechos ajenos, los que deben ser considerados por el tercero si tenía conocimiento de su existencia, o no puedan desconocer su existencia ${ }^{21}$. A la vez, el profesor Enrique Barros se cuestiona si el incumplimiento de un contrato puede dar lugar a responsabilidad extracontractual en contra del tercero que hace imposible dicho incumplimiento. Sobre ello, plantea que la sola negligencia del tercero no da lugar a hacer valer en su contra, responsabilidad en favor de las partes

\footnotetext{
${ }^{20}$ Bustamante (2006), p. 377.

${ }^{21}$ Bustamante (2006), pp. 379 y ss.
} 
del contrato; para ello se requeriría la mala fe del tercero ${ }^{22}$; específicamente, el caso que podría dar lugar a responsabilidad es aquel en que el tercero induce al deudor al incumplimiento, teniendo pleno conocimiento de que dicha interferencia traerá consigo ese efecto ${ }^{23-24}$. Al parecer, no es factible pronunciarse en forma tajante en términos positivos o negativos acerca de la procedencia de la responsabilidad civil del tercero causante de la interferencia, teniendo presente el amplio espectro de situaciones que pudieren quedar bajo el paraguas del daño por intromisión ${ }^{25}$.

\section{Algunas respuestas del derecho extranjero y uniforme}

En España, la cuestión sobre la eventual restitución de los lucros obtenidos por el incumplimiento del deudor ha sido debatida con cierta intensidad, como recuerda Díez Picazo ${ }^{26}$, resaltando muy especialmente las opiniones de Pantaleón Prieto que, a propósito del caso en que el deudor enajena la cosa debida a un tercero, sustenta que el acreedor estaría facultado a optar entre que su deudor le ceda la pretensión a la contraprestación debida por el tercero, o bien, la entrega de lo ya satisfecho por éste, siendo perfectamente posible que este último valor sea superior al monto de los perjuicios que pudiere obtener del deudor fundado en su incumplimiento ${ }^{27}$. En efecto, Pantaleón previene que no obstante no es función de la responsabilidad civil evitar que el deudor se enriquezca como efecto del incumplimiento, nada obstaría que, conforme a lo

\footnotetext{
22 Barros (2006), p. 997.

${ }^{23}$ Barros (2006), p. 999.

${ }^{24}$ En alguna doctrina foránea, el daño por intromisión es concebido en términos vastos, incorporando situaciones muy diversas, como la violación del crédito que reconoce el derecho de alimentos, si se da muerte en forma dolosa o culposa al alimentante por un tercero; la destrucción o deterioro de una cosa debida por parte de un tercero. Cano Martínez de Velasco (2007), p. 104. Incluso, se incluyen casos más complejos, como la violación de un acuerdo de exclusividad comercial por parte de terceros competidores, p. 14

${ }^{25}$ En efecto, los casos van desde la intervención de terceros que impiden la celebración de un contrato, por ejemplo, si ofrece a uno de los negociantes mejores condiciones; aquellos en que terceros provocan que se celebre entre las partes un contrato ineficaz, por ejemplo, por medio de una acción u omisión dolosa; hasta las hipótesis en que interfiere en el contrato impidiendo, total o parcialmente, el cumplimiento. En esta última categoría no sólo habría que situar las situaciones en que se celebra con un tercero un contrato más favorable, como el objeto de nuestro estudio, sino cualquier otra hipótesis en que a causa de una acción u omisión del tercero el contrato se torna imposible de ser cumplido. Domínguez - Domínguez et al. (1996), pp. 179-183; Barros (2006), p. 1008; Segura (2007), p. 350; Cano Martínez de Velasco (2007), pp. 65-167.

${ }^{26}$ Díez Picazo (2007), p. 1601.

27 Díez Picazo (2007), pp. 1601 y ss.
} 
dispuesto en el artículo 1186 del CC. español ${ }^{28}$, "el deudor deba el beneficio que obtiene del incumplimiento"29. De consiguiente, la disposición citada no sólo facultaría al acreedor a obtener el commodum ex re, sino también el commodum ex negotiatione ${ }^{30}$. Como señala Díez Picazo, esa idea también ha sido sustentada por Xabier Basozábal, al sostener que el ordenamiento jurídico otorga al acreedor el "monopolio de las utilidades de la cosa", esto es, los frutos del goce de la misma y el precio por disposición de ella ${ }^{31}$. Por lo demás, hay que adicionar que en la misma obra de Basozábal citada por el profesor Díez Picazo, el primero agrega que aunque la doctrina concuerda en una separación entre el fenómeno resarcitorio y la pretensión de restitución del enriquecimiento, nada obsta a que ambas pretensiones sean plenamente compatibles, o la segunda subsidiaria de la primera, precisamente porque persiguen fines diversos ${ }^{32}$. En un supuesto distinto al de este trabajo, pero relevante en la forma de razonamiento y comentando el derecho alemán, el profesor Basozábal adiciona que si el deudor ha enajenado una cosa ajena, ha prevalecido el criterio según el cual es posible obtener "la restitución de todo lo obtenido en virtud de la enajenación (commodum ex negotiatione)" ${ }^{\prime 33}$.

Distinta es la opinión de otro sector de la doctrina, como la de Carrasco ${ }^{34}$, quien al analizar el alcance del artículo 1186 ya señalado, expone que si el vendedor que aún no ha entregado la cosa, la vende nuevamente a mejor precio, el primer comprador sólo puede demandar el precio de la primera venta pagado y la indemnización de los daños, mas no el mayor precio obtenido en la segunda venta $^{35}$. Como previene el mismo Díez Picazo, resulta difícil extraer una regla

${ }^{28}$ Que dispone: "Extinguida la obligación por la pérdida de la cosa, corresponderán al acreedor todas las acciones que el deudor tuviere contra terceros por razón de ésta".

29 Pantaleón (1991), p. 1022.

30 PANTAlEón (1991), p. 1022 "Si el deudor enajena a un tercero la cosa debida, el acreedor podrá optar por exigir de aquél, con apoyo en el mencionado precepto, la cesión de la pretensión a la contraprestación debida por el tercero, o la entrega de lo ya satisfecho por éste; alternativa que interesará especialmente al acreedor, cuando, con ella, pueda obtener una suma mayor que la que conseguiría, como indemnización de daños y perjuicios, por la vía de la responsabilidad contractual". PANTALEón (1993), p. 1737.

${ }^{31}$ Díez Picazo (2007), p. 1602.

32 Basozábal (1998), p. 104.

33 Basozábal (1998), p. 198.

${ }^{34}$ En una cuestión vinculada, Carrasco se pregunta por la restitución al dueño de la cosa, de aquella ganancia obtenida por quien no es dueño de ella, si cedió dicho uso a un tercero, y considera que es factible sustentar esa pretensión, fundado en los principios generales de la prueba del daño. CarRAsCo (1988), p. 65.

${ }^{35}$ CARRASCO (1988), p. 144. 
del artículo 1186, según la cual al acreedor le pertenece el commodum si el deudor ha enajenado la cosa a un tercero ${ }^{36}$. Con todo, se ha entendido que en la reforma española, el derecho de obligaciones y contratos contemplaría el commodum ex negotiatione, en la segunda parte del artículo $1196^{37}$.

El panorama puede resultar diferente en el derecho alemán, en que con base al actual $\S 285^{38}$, se podría sustentar de parte del acreedor el derecho a tal commodum ex negotiatione ${ }^{39}$. Una actitud ligeramente distinta se ha tenido en el derecho anglosajón, pues si bien la regla ha sido denegar ante un incumplimiento contractual que el acreedor obtenga la restitución de los beneficios, en algunos casos calificados ello se ha admitido ${ }^{40}$, especialmente cuando se está ante situaciones en que los remedios tradicionales no se consideran del todo apropiados $^{41}$. Resalta, entre los autores que siguen esta línea, Peter Birks, que,

36 Díez Picazo (2007), p. 1607.

37 FENOY (2011), p. 1555.

${ }^{38}$ La norma dispone: "(1) Si como consecuencia de la circunstancia por la cual, según el § 275, apartados 1 a 3, no debe cumplir la prestación el deudor obtiene un resarcimiento o una pretensión de resarcimiento por el bien debido, el acreedor puede exigir la restitución de lo recibido como resarcimiento o la cesión de la pretensión de resarcimiento.

(2) Si el acreedor puede exigir resarcimiento del daño en lugar de la prestación, ésta se reduce, si se hace uso del derecho previsto en el apartado 1, en la medida del valor del resarcimiento obtenido o de la pretensión de resarcimiento".

${ }^{39}$ Esto no resulta extraño para el derecho alemán, pues también se ha consolidado un mecanismo de triple modo de cálculo de daño en acciones indemnizatorias concedidas por leyes especiales, particularmente en sede de propiedad industrial. Es así que en el cómputo del daño, el acreedor puede optar entre la forma tradicional de cálculo del lucro cesante; la cantidad que hubiera tenido que abonar el demandado como cesionario del derecho usurpado; o la ganancia que el intromisor ha obtenido. BASOZÁBAL (1997), p. 1265. En todo caso, este sistema de cálculo es usualmente utilizado en sede de propiedad intelectual o industrial, incluso en nuestro país, como se evidencia, por ejemplo, en el artículo 85 E de la Ley $N^{\circ} 17.336$, sobre propiedad intelectual, que permite condenar al infractor a pagar las ganancias que éste haya obtenido. Un análisis similar se constata en otro trabajo del profesor Díez Picazo, en relación a las leyes especiales sobre patentes e intrusiones mineras. Dí́zz Pıcazo (2007), pp. 207-216.

${ }^{40}$ A tal efecto, se citan algunos casos como "City of New Orleans v. Fireman's Charitable Association; en este caso, los demandados habían celebrado un contrato mediante el cual se obligaban a disponer de cierta capacidad para combatir el fuego, lo que no se cumplió, aunque no se produjo ningún siniestro, por lo que la actora solicitó la restitución del ahorro de gastos, pues no existieron perjuicios susceptibles de ser indemnizados; la demanda fue desechada. En Wrotham Estate Homes Ltd. v. Parkside Homes $L t$ d., la demandada se obligó a construir un complejo de casas bajo ciertas especificaciones que no fueron respetadas. La demandante solicitó el cumplimiento del contrato lo que implicaba la destrucción de las casas, ello fue desechado por la justicia resolviendo, en cambio, la restitución de los beneficios, pero de una forma similar al cálculo del lucro cesante. Barros (2009), pp. 48 y s. KahNEMAN y TVERSKY (2000), p. 443.

${ }^{41}$ Campbell y Harris (2002), pp. 2010 y s. 
como se sabe, es a quien se debe en gran medida el reconomiento que hoy tiene el derecho de restituciones ${ }^{42}$.

Como se ve, atendido el estado de la discusión, no es habitual que los sistemas jurídicos se ocupen de regular esta situación de hecho. Algo similar es factible predicar del derecho uniforme. Así, en lo que refiere a los PECL, podríamos inferir que habría dificultades en sustentar un derecho por parte del acreedor a las ganancias obtenidas, pues el artículo 9.501 dispone que la parte perjudicada está facultada para reclamar una indemnización de perjuicios por la pérdida que le hubiere causado el incumplimiento de la otra parte, a menos que se encuentre en una causal de exoneración. Esto supone que la medida de la reparación es el daño experimentado y no la ganancia del deudor. A la vez, el artículo 9.502 señala que el parámetro del cálculo de daños corresponde a aquella suma que sitúe a la parte perjudicada en la situación más semejante posible a la que se encontraría si el contrato se hubiere cumplido debidamente, y que la indemnización cubre las pérdidas que la parte perjudicada ha sufrido y la ganancia que se ha dejado de obtener. Sobre el sistema de cálculo de los daños contenidos en los PECL, se ha señalado que este principio deberá concretarse de acuerdo a la manifestación que tenga el incumplimiento en cada caso y los efectos que ello genere en el acreedor, además de las medidas que éste adopte ${ }^{43}$. Algo parecido se visualiza en los Principios Unidroit, en particular, si se atiende al tenor de normas tales como el artículo 3.2.16, y muy especialmente el artículo 7.4.2. La CESL, por su parte, exige que el acreedor sufra pérdidas, por lo que, incluso, no se admite la figura de los daños meramente nominales o nominal damages, propios del derecho anglosajón ${ }^{44}$. En el mismo texto, el artículo 160 establece como medio de determinación del quantum indemnizatorio el Ilamado principle of full compensation, que en el derecho uniforme se contiene en las normas de los artículos 9:502 PECL y III, 3:702 del MCR, cuyo propósito es dejar al acreedor indemne, contemplando el daño emergente y el lucro cesante ${ }^{45}$. En los recientes PLDC ocurre algo similar, pues no hay norma alguna que permita

42 Basozábal (2018), p. 15; BiRks (2014), p. 13. Agrega el mismo Basozábal, que en un reciente Congreso realizado en abril de 2017, cuyas actas aún no han sido publicadas, Gerhard Dannemann postuló que el contrato no permite que el contratante incumplidor se quede con la ganancia obtenida del incumplimiento. BASOzÁBAL (2018), p. 39. Por lo demás, Dannemann, ya había adelantado algunas de esas ideas anteriormente. DANNEMANN (2009), pp. 210-213.

43 Díez Picazo-Roca Trías et al. (2002), p. 374.

44 ZURITA (2015), p. 673.

45 ZURITA (2015), p. 676. 
sustentar que es procedente para el acreedor obtener la restitución de ganancias obtenidas por el deudor derivadas de su incumplimiento ${ }^{46}$.

Lo anterior es comprensible, sobre todo si se considera que tales cuerpos normativos no contemplan en sus regulaciones a la figura del enriquecimiento injustificado. De ahí que traer a colación al MCR sea relevante en este punto. En efecto, el artículo III 3:702 prácticamente reproduce lo señalado en los PECL ${ }^{47}$; sin embargo, el Libro VII regula con un interesante grado de pormenoridad al enriquecimiento injustificado, aunque igualmente nos parece que, si se atiende al contenido de su articulado, resulta forzado construir una facultad del acreedor de obtener restitución de ganancias, sobre todo considerando el alcance del artículo VII. 2:101, que regula las circunstancias en las que el enriquecimiento es injustificado; el artículo VII. 3:101, que norma qué debe entenderse por enriquecimiento ${ }^{48}$; el artículo VII. 3:102, que refiere a los casos en que se está ante una desventaja ${ }^{49}$; y finalmente, conforme al tenor del artículo VII. 4:101, que explica cuándo el enriquecimiento se obtiene a costa de otro.

\section{Sobre la cuestión en el derecho chileno}

En una primera aproximación, cabe preguntarse cuál es el tratamiento que nuestros autores han brindado a la temática de la restitución del commodum ex negotiatione, fundado en lo dispuesto en el artículo 1677 CCCh., homologando la discusión del derecho español antes expuesta. Sobre el particular, la mayor

${ }^{46}$ De la Maza-Pizarro et al. (2017), pp. 70-75.

${ }^{47}$ Artículo III 3:702 "Cuantía global de la indemnización.

La cuantía global de la indemnización por los daños causados por el incumplimiento de una obligación es la suma de dinero que coloque al acreedor, de la manera más próxima posible, en la situación en que se hubiere encontrado si la obligación hubiere sido debidamente cumplida.

La indemnización cubre las pérdidas que el acreedor haya sufrido y las ganancias que haya dejado de obtener".

${ }^{48}$ Con la sola finalidad de graficar lo señalado, el artículo VII. 3:101 dispone: "Enriquecimiento.

(1) Una persona se enriquece mediante:

(a) el incremento de activos o la disminución de obligaciones; o

(b) la recepción de un servicio u otra prestación análoga; o

(c) el uso de activos ajenos.

(2) Para determinar si y en qué medida, una persona se enriquece, no deberá tenerse en cuenta la desventaja que dicha persona soporte a cambio o como consecuencia del enriquecimiento".

${ }^{49}$ VII. 3: 201 "Desventaja.

(1) Una persona soporta una desventaja por:

(a) la disminución de activos o el incremento de obligaciones; o

(b) la realización de un servicio u otra prestación análoga; o

(c) el uso que otro hace de sus activos.

(2) Para determinar si y en qué medida, una persona soporta una desventaja, no deberá tenerse en cuenta el enriquecimiento que dicha persona obtenga a cambio o como consecuencia de esa desventaja". 
parte de nuestra doctrina se limita a reproducir lo dispuesto en ese artículo, sin entrar en mayores honduras, salvo un trabajo del profesor Jaime Alcalde ${ }^{50}$, quien aborda el estudio del commodum ex negotiatione brevemente, pues su centro de atención es el commodum representationis. Es así, que su estudio se sitúa especialmente en dos aspectos del artículo en comento: primero, en tanto se trataría de otra manifestación de la protección que el ordenamiento jurídico brinda al acreedor, pues intenta morigerar los perjuicios padecidos por éste ante la imposibilidad de la prestación, evitando, a su turno, que el deudor se enriquezca indebidamente si se permitiera a este último obtener del tercero que provocó la imposibilidad, un beneficio económico ${ }^{51}$. En segundo lugar, estudia la naturaleza que han de tener las obligaciones a que es factible aplicar la figura del commodum repraesentationis, concluyendo que no obstante la disposición se referiría a las obligaciones de dar especie o cuerpo cierto, también sería admisible para las obligaciones de simple entrega material, si la cosa ha sido destruida o deteriorada por un tercero ${ }^{52}$. Por el contrario, que el deudor ceda al acreedor las acciones que el primero tiene contra el tercero que torna imposible la obligación de hacer, sería mucho más discutible; por una parte, si se trata de obligaciones genéricas y de hacer fungibles, el acreedor puede satisfacer su interés igualmente; y tratándose de obligaciones de hacer no fungibles es complejo, debido a que se afectaría la esfera personal del deudor ${ }^{53}$. Es en este ambiente que Alcalde se aproxima al commodum ex negotiatione, y citando a Von Thur y a nuestro artículo 1678 CCCh. afirma que dicho commodum se avalúa objetivamente en el precio de la misma y, por ello, aparentemente acogiendo la posibilidad de que éste sea susceptible de ser obtenido del deudor que ha enajenado la cosa ${ }^{54}$.

Desde otra perspectiva, hay que destacar la opinión del profesor Enrique Barros, quien se muestra, en general, poco proclive a permitir que el acreedor accione contra el deudor para obtener la restitución de las ganancias. En efecto, varios son los argumentos que el profesor Barros expone, en su mayoría referidos al derecho foráneo. Nosotros reproduciremos algunos de ellos, debido a que se trata de uno de los pocos especialistas nacionales que han tocado la problemática con mayor rigor. De una parte, apunta a que los avatares que se desarrollan en sede contractual deben necesariamente resolverse al interior del mismo,

\footnotetext{
50 Meza (1994), p. 483; Abeliuk (2009), p. 1173; Barcia (2010), p. 198.

51 AlCalde (2009), p. 487.

52 Alcalde (2009), pp. 493 y s.

53 Alcalde (2009), p. 495.

${ }^{54}$ Alcalde (2009), p. 500.
} 
siendo irrelevante lo que ocurre fuera de la convención, a más del hecho que admitir la restitución de ganancias tendría un alcance de instrumento punitivo, ajeno al derecho privado. A la vez, si se acepta el incumplimiento eficiente, la restitución de ganancias precisamente iría en sentido contrario, pues implicaría sustentar que el contrato debería ser cumplido ${ }^{55}$. Agrega que hay una serie de dificultades para sustentar dicha restitución, entre ellas, que el beneficio que el deudor obtiene no necesariamente deriva directamente de su incumplimiento, sino que puede provenir de circunstancias de distinta naturaleza, como la misma habilidad del deudor, lo que genera problemas de relación de causalidad ${ }^{56}$. En seguida, destaca la postura seguida en el derecho anglosajón, exponiendo que la regla general en ese sistema es el rechazo al derecho del acreedor a obtener las ganancias, salvo en contados casos, entre ellos ${ }^{57}$, el de los incumplimientos inescrupulosos, en que evoca los artículos 1458 y 2316 del CCCh., normas que interpretadas en forma extensiva permitirían sustentar la tesis de que los beneficios que provienen del dolo deberían ser restituidos por parte del deudor doloso. Con todo, luego observa nuevamente que una interpretación en esa línea daría lugar a reconocer que la pretensión del acreedor sería meramente punitiva, lo que carecería de justificación ${ }^{58}$. En forma reciente, en términos muy similares a lo expuesto tiempo antes por el profesor Barros, el profesor Alberto Pino ha abordado esta materia, pero en forma incompleta, como él mismo lo reconoce $^{59}$, pues además de fundarse en principios de la teoría del derecho, se circunscribe especialmente a lo dispuesto en los artículos 1458 inciso segundo y 2316 CCCh. ${ }^{60}$, basándose, especialmente, en la experiencia del derecho anglosajón; así, plantea que en caso de un incumplimiento doloso y por culpa grave, se daría lugar a la restitución de las ganancias obtenidas por el deudor; en tal sentido, considera que para estos efectos el dolo es un incumplimiento intencional, aunque sin que sea necesario que tal intención implique proferir

\footnotetext{
55 Barros (2009), pp. 41 y s.

56 Barros (2009), pp. 43 y s.

57 "Los incumplimientos cínicos o inescrupulosos; los casos en que los jueces niegan lugar a la acción de ejecución en naturaleza, en ejercicio de su potestad valorativa de acuerdo a la equity, de modo que la acción sobre los beneficios es reconocida en vez de esa ejecución en naturaleza; y en tercer lugar, en algunos casos en que el acreedor sufre perjuicios meramente nominales y se estima darle una satisfacción con cargo a los beneficios que el deudor ha obtenido de su incumplimiento". Barros (2009), pp. 47 y s.

58 Barros (2009), pp. 57 y s.

${ }^{59}$ PINO (2016), p. 265.

60 PINO (2016), pp. 254 y s.
} 
daño al acreedor ${ }^{61}$. Finalmente, también en la línea del profesor Pino, el profesor Momberg, en una tesis completamente contraria a la nuestra ${ }^{62}$.

En lo que refiere a nuestos tribunales de justicia, hay que reconocer que no hay jurisprudencia específicamente sobre este dilema, aunque nos parece excepcionalmente interesante una sentencia pronunciada por la Corte de Apelaciones de Concepción con fecha 17 de julio de 2014 ${ }^{63}$, a pesar de que no se enmarca en forma absoluta con el problema que nos ocupa. En efecto, se trata de un contrato de mandato en que el mandante encarga al mandatario vender dos lotes de terreno, a cambio de una remuneración consistente en el diez por ciento del precio de la compraventa que se realizará de los mismos. Habiendo transcurrido nueve años desde la celebración del contrato sin que el mandatario llevara a cabo ninguna gestión, el mandante y dueño de los inmuebles finalmente los vende, pero luego es demandado por el mandatario, solicitando el pago de veinte millones de pesos, correspondientes al porcentaje del precio de la compraventa. La sentencia de primera instancia acoge la demanda, pero la de segundo grado la revoca, rechazando la demanda. El razonamiento de la Corte se funda en la relevancia del principio de enriquecimiento sin causa. Así, la Corte observa que "en el caso sub lite, cobra especial relevancia el principio del 'enriquecimiento sin causa', aquel principio general del derecho, según el cual el orden normativo repudia el enriquecimiento a expensas de otro sin causa que lo justifique. Bajo este principio, se trata de exigir a todo enriquecimiento, una causa que lo justifique". Por ello, agrega el Tribunal, que "en este caso el mandatario no desarrolló con éxito actividad alguna, mal puede pretender entonces obtener remuneración o estipendio o indemnización alguna", y luego concluye: "Dicho de otra manera, no cabe sino interpretar la cláusula controvertida en el sentido que el demandante debe haber participado de la venta de los sitios, para recibir el pago del diez por ciento del precio, de otra forma se estaría permitiendo un enriquecimiento sin causa, que es lo que el derecho no quiere ni permite".

Hemos optado por transcribir algunos párrafos del fallo en comento, por dos razones, la primera, es que ciertamente que en este caso la mandante no pretende que el mandatario le restituya nada, de hecho no cabría aludir a un enriquecimiento por parte de esta última; como se dijo, es el mandatario el que intenta que se le pague la remuneración acordada, sin embargo, la relevancia

\footnotetext{
${ }^{61}$ PINO (2016), pp. 254 y s.

62 Momberg (2017), pp. 421-432.

${ }^{63}$ Rol No $106 / 2014, N^{\circ}$ identificador vlex 577689594.
} 
de esta sentencia radica en que aplica como principio general al enriquecimiento justificado con la finalidad de rechazar la pretensión del mandatario, pues, de lo contrario, éste se enriquecería sin causa. Ello permite colegir que para el Tribunal nada obsta razonar sólo sobre la base de este principio en sede contractual, precisamente para rechazar una acción fundada en un supuesto incumplimiento contractual. Ello deja en evidencia que, como hemos afirmado, hay grupos de casos en que este principio entra a jugar un papel relevante en sede contractual. La segunda razón, es que resulta interesante que nos situemos en el siguiente escenario hipotético: si el mandante hubiera pagado todo o parte de la remuneración y el mandatario llevado a cabo algunos actos tendientes a cumplir con el encargo, pero quien vende el lote es el dueño, entonces ante un cumplimiento imperfecto y con un razonamiento similar, el mandante podría haber solicitado una reducción proporcional de la remuneración, en consonancia con aquella postura que hemos mantenido, según la cual la acción de rebaja proporcional del precio tiene un ámbito de aplicación más general. Volveremos sobre ello unas líneas más adelante.

\section{Nuestra opinión}

A juicio nuestro, no es procedente que el acreedor pretenda la restitución de las mayores ganancias obtenidas por el deudor. Ello, atendido las siguientes razones: primero, porque no hay argumentos dogmáticos que posibiliten sustentar una postura en tal sentido, no siendo procedente, por ejemplo, aplicar por analogía lo dispuesto en los artículos 1458, inciso segundo y 2316 CCCh.; y, en segundo término, porque el acreedor carece de interés para pretender tales utilidades, puesto que el ordenamiento jurídico le proporciona los Medios necesarios para hacer frente al incumplimiento eficiente del deudor. Veamos, pues, ambos órdenes de argumentaciones.

\subsection{Ausencia de argumentos dogmáticos que sustenten la restitución de ganancias}

\section{a) Sobre la improcedencia de demandar las ganancias a través de la acción in rem verso}

Como hemos dejado en evidencia, es posible visualizar un grado de conexión entre el problema que se aborda y el principio según el cual el derecho repudia que una persona se enriquezca injustificadamente a costa de otra, de modo que podría resultar útil acudir a él para sostener la viabilidad de una demanda del acreedor en contra del deudor, con el fin de obtener que este último le entregue la ganancia experimentada gracias a su incumplimiento, con el fundamento de que no obstante no ha habido empobrecimiento por parte 
del acreedor, el deudor ha experimentado un enriquecimiento injustificado ${ }^{64}$. Sin embargo, nos parece que la aplicación del instituto del enriquecimiento sin causa no está exenta de problemas. Y es que aunque es fácil advertir que en nuestro país se tiende a recurrir al enriquecimiento sin causa como ultima ratio para sustentar las más variadas peticiones ante los tribunales de justicia ${ }^{65}$, ello no siempre es adecuado para todos los casos, de ahí que se debe abordar esta figura con cautela ya que presenta una serie de complejidades que parten, incluso, con el problema de la denominación ${ }^{66}$.

Como se sabe, una de las mayores influencias de la doctrina sobre esta materia proviene de la tradición alemana, que en este ámbito es muy diversa a la del derecho de raigambre francesa, por lo que no resulta del todo posible trasladar la totalidad de estas concepciones a nuestro derecho. Posiblemente, esa es una de las razones por las cuales algunos especialistas postulan que no sería procedente construir un principio general meramente abstracto según el cual se debe repudiar todo enriquecimiento injustificado, sino que más bien se propone un camino intermedio, que implica identificar una tipología referida a estos casos. En ella, habría que distinguir entre las condictio por prestación, por intromisión y por inversión o desembolso ${ }^{67}$. Entre esas condictio, se ha postulado por algunos que la restitución de las mayores ganancias del deudor al acreedor, podría constituir un caso de condictio por intromisión ${ }^{68}$, pues el deudor se habría entrometido en el derecho del acreedor a que le cumplan.

\footnotetext{
${ }^{64}$ Considerando aquella postura que sustenta que lo determinante para configurar al enriquecimiento injustificado como fuente de obligaciones, no es el empobrecimiento, sino el enriquecimiento que un patrimonio experimenta en forma injustificada. PeÑAILILlo (1996), pp. 15 y s.

${ }^{65}$ En efecto, tales pretensiones van desde el reclamo de indemnizaciones adicionales en procesos de expropiación, como en sentencia de la Corte Suprema de 27 de julio de 2004 -pretensión finalmente rechazada-, atendido el tenor literal del artículo 38 del D.L. № 2.186-; hasta la de obtener diversos rubros indemnizatorios en acciones de responsabilidad civil contractual, como en la sentencia de fecha 2 de junio de 2016 pronunciada por la Corte Suprema, referida al cobro de una pena debido al incumplimiento de un contrato de arrendamiento de inmueble, cobro que la demandada consideraba que enriquecería injustificadamente a la actora, pues la misma tendría una naturaleza indemnizatoria, en circunstancias que no se habrían producido tales perjuicios. Esta argumentación es desechada por la Corte, atendido que la cláusula penal no tiene el carácter de indemnización de perjuicios, siendo incorrecta la calificación de "avaluación anticipada y convencional de los perjuicios", Ilevada a cabo por la doctrina más antigua, pues se trata más bien de una sanción punitiva, conminatoria al cumplimiento, por lo que, habiendo incumplimiento, procede dar lugar a su pago, rol № 6528/2015, $N^{\circ}$ identificador vlex 641575669.

${ }^{66}$ Díez Picazo (1988), p. 60.

${ }^{67}$ Díez Picazo (1988), p. 97.

68 ZimmermanN (2000), p. 253.
} 
En esa línea, si bien sería factible apelar al repudio que como principio manifiesta nuestro sistema jurídico al enriquecimiento sin causa y, además, argumentar que puede erigirse como fuente de las obligaciones si se reúnen determinados requisitos ${ }^{69}$, aunque no esté expresamente establecido en nuestro derecho $^{70}$, nos parece que hay dificultades insoslayables atendido el estado actual de nuestro derecho.

En primer lugar, es efectivo que debido a que en nuestro sistema jurídico no hay una regulación general del enriquecimiento injustificado $-y$, por ende, de la acción in rem verso-, pero tampoco pormenorizado de todos y cada uno de los casos en que podría verse reflejada esta institución, podría ser sustentable la viabilidad de recurrir al ejercicio de la acción. Sin embargo, nos parece que incluso en los casos en que no exista otro medio adecuado para el demandante, resulta cuestionable admitir, sin más, el ejercicio de dicha acción ${ }^{71}$. En esa línea, concordamos con los llamados de cautela que mucha doctrina formula acerca de los peligros de expandir en forma indiscriminada al enriquecimiento injustificado, especialmente si de lo que se trata es de dejar de aplicar los principios y la lógica del derecho de contratos.

En segundo lugar, es que, como se dirá líneas más adelante, el acreedor cuenta con acciones que puede ejercer ante un caso de incumplimiento eficiente; es efectivo que probablemente la acción de indemnización de perjuicios no sea del todo relevante en los casos que nos ocupan, pero en el catálogo de derechos o remedios contractuales hay, al menos, dos que parecen perfectamente idóneos para el propósito de dar una adecuada respuesta a los intereses de ambas partes conrtratantes: la rebaja proporcional del precio y la resolución por incumplimiento. En ese orden, aunque se trata de un carácter bastante discutible, nos parece que la exigencia de subsidiariedad de la acción de restitución impediría o, siquiera, dificultaría recurrir al enriquecimiento sin causa como argumento relevante a la hora de afirmar la procedencia de la restitución de las ganancias derivadas del incumplimiento eficiente, puesto que habría una prelación normativa de acciones que se debe respetar ${ }^{72}$.

\footnotetext{
${ }^{69}$ Que en los derechos que se reconoce, son más o menos similares. Drson-Goudkamp et al. (2016), p. 5.

${ }^{70}$ A diferencia de lo que ocurre con la reforma al derecho de obligaciones francés que entró en vigencia el 1 de octubre de 2016, en que se recoge en forma expresa como fuente de las obligaciones al enriquecimiento injustificado.

${ }^{71}$ Morales (2017), p. 608. Sobre ello, el profesor Morales Moreno, comentando la reforma francesa, apunta que antes de la reforma, la cuestión quedaba entregada a los jueces, los que incluso en casos iguales, resolvieron de forma diversa acerca de la procedencia o improcedencia de la acción in rem verso.

${ }^{72}$ Sobre las diversas acepciones de subsidiariedad de la acción in rem verso, OrOzCO (2015), pp. 339-344.
} 
En efecto, tanto en la doctrina nacional, como en la foránea, con matices, se observa la tendencia a exigir que la acción a que da lugar el enriquecimiento injustificado, que, en general, se la identifica con la actio in rem verso ${ }^{73}$, sólo puede ejercitarse en caso que no exista otra acción o medio idóneo específico para solucionar el problema ${ }^{74}$. Tan asentado es este carácter, que la reciente reforma al derecho de obligaciones francés, que regula en forma pormenorizada al enriquecimiento injustificado, lo acoge en el artículo 1303-375. La jurisprudencia chilena ha aplicado este requerimiento en gran cantidad de causas. Así, a vía meramente ejemplar, en un caso fallado recientemente por la Corte Suprema ${ }^{76}$, en que se ejerce la acción referida, fundada en que se habría encargado por la demandada a la actora la construcción de una serie de obras, al margen de aquellas que fueron adjudicadas a la demandante mediante proceso de licitación, obras que habrían alterado sustancialmente lo pactado en los contratos licitados, por lo que ellas le habría provocado un empobrecimiento, de modo que solicita la restitución de las sumas adeudadas por los costos que implicó la construcción de estas nuevas obras. Los jueces del fondo desecharon la demanda, precisamente por no cumplirse el requisito de que la acción in rem verso es subsidiaria, en tanto la actora contaba con otros medios para obtener la satisfacción de sus intereses. En este caso, el fundamento fue que las obras se adjudicaron a una empresa constructora, la que luego celebró con otra empresa un contrato de asociación de cuentas de participación, que fue la que finalmente realizó las obras y demandó en juicio. Con posterioridad, la empresa adjudicataria cayó en insolvencia, lo que generó su quiebra. Esta es la razón por la cual los jueces del fondo desecharon la acción in rem verso, pues estimaron que la demandada debió hacer valer sus créditos en contra de la empresa adjudicataria en el marco del proceso de quiebra. Y es que en nuestro país, los tribunales han recurrido al requisito de la subsidiariedad de la acción para desecharla, con las más diversas motivaciones, entre ellas, el reconocimiento de la naturaleza excepcional que reviste la acción ${ }^{77}$.

\footnotetext{
73 Peñailillo (1996), p. 10.

74 Peñailillo (1996), p. 24.

${ }^{75}$ La norma dispone: "El empobrecido no tiene acción de enriquecimiento injustificado cuando puede ejercitar otra acción o el ejercicio de ella está impedido por un obstáculo jurídico, como la prescripción".

${ }^{76}$ Sentencia de la Corte Suprema de fecha 25 de abril de 2017, rol № 87738-2016.

77 "En este último sentido, se debe señalar que si bien el principio jurídico que prohíbe enriquecerse a costa de otra persona si no existe una causa legitima que lo justifique, constituye una herramienta aplicable en prácticamente todos los ámbitos del derecho, la acción que se otorga a quien sufre un empobrecimiento incausado, es excepcional y subsidiario, que sólo tiene aplicación cuando no queda ninguna otra vía para el reclamo, requisito éste que, tal como sostienen los sentenciadores del fondo, en la especie no concurre, por existir otras vías procesales para reclamar de ello", considerando octavo, sentencia de la Corte Suprema, rol No 27477/2014, de fecha 20 de abril de 2015.
} 
Si se mira este aspecto más de cerca, resulta que hay diversas acepciones del concepto de subsidiariedad ${ }^{78}$, que obedecen a las distintas motivaciones que ha tenido la jurisprudencia -española, en este caso-, para desechar la acción, entre ellas, si existe o no un medio para obtener el objeto preciso de la pretensión. Así, podría argumentarse que la exigencia de la subsidiariedad implicaría que si existe otro medio a través del cual se obtenga exactamente lo mismo que lo que se pretende con la acción in rem verso, la acción debiera desecharse. Por consiguiente, toda vez que en nuestro derecho no habría otra acción que permita en forma precisa lograr que el deudor restituya los beneficios obtenidos por su incumplimiento, se cumpliría el requisito de que la acción tenga el carácter de subsidiaria.

Sin embargo, nos parece que en derecho contractual la subsidiariedad de la acción no sólo supone determinar si hay o no una acción que persiga el preciso objeto que el demandante procura -en este caso, la restitución de las ganancias otenidas del incumplimiento-, sino que ello debe articularse o armonizarse con dos ideas matrices adicionales: la primera, es que en el ambiente contractual, el acreedor cuenta con una serie de medios o derechos que cubren todas las posibles pretensiones que pudieren derivar de su incumplimiento: no sólo los remedios derivados de tal incumplimiento, sino que incluso las acciones que cautelan la validez del contrato protegen, asimismo, sus intereses, lo que se denota, sobre todo, en aquellas situaciones en que un vicio causal de ineficacia, repercuta en el contenido de la convención ${ }^{79}$. Siendo así, estas acciones o derechos son los que han de prevalecer ${ }^{80}$, restringiéndose más que en otros ámbitos, la aplicabilidad de la acción en comento. La segunda idea es que, si bien es cierto no hay ninguna acción que permita al acreedor obtener la restitución de las ganancias obtenidas por el deudor, hay un principio fundamental,

\footnotetext{
${ }^{78}$ La primera, que supone una limitación al derecho de recurrir al principio de enriquecimiento injustificado por considerarse excepcional; la segunda, implica rechazar la acción en caso que falte el requisito de ausencia de causa, acepción que tampoco alude con precisión al requisito en comento; la tercera, refiere a los casos en que no hay enriquecimiento de parte del demandado y/o empobrecimiento del demandante, por lo que la acción se rechaza; la cuarta que "aparece directamente relacionada con la tipicidad o atipicidad de la acción restitutoria a ejercitar, sosteniéndose entonces por la jurisprudencia que no puede ejercitarse una acción de enriquecimiento injustificado de carácter general, basada en el principio general que obliga a la restitución de todo enriquecimiento injustificado, cuando exista una acción específica para obtener la restitución de dicho enriquecimiento", Orozco (2015), p. 340; y finalmente, en caso que se produzca un enriquecimiento indirecto por intermediación de un tercero, la subsidiariedad refiere a que se puede ejercer la acción en contra de este tercero, si no se puede obtener del titular del patrimonio que inicialmente obtuvo el enriquecimiento. Para el autor, las dos últimas acepciones son las correctas, p. 343.

79 PRADO (2016), pp. 442-444.

${ }^{80}$ WadDAMS (2008), p. 169.
} 
como es que es la de equilibrio o conmutatividad de la relaciones entre las partes del contrato: a eso tienden los derechos conferidos por el ordenamiento jurídico. De modo que, habiendo derechos o acciones que le permiten al acreedor recuperar ese equilibrio transitoriamente perdido, esos derechos son los que deben prevalecer.

\section{b) Inadecuación de lo dispuesto en los artículos 1458, inciso segundo y 2316 CCCh. al incumplimiento eficiente}

Es necesario, ahora, detenernos en los artículos 1458, inciso segundo y 2316 CCCh., puesto que no sólo parece que regularían situaciones muy similares a las que son objeto de nuestro estudio, sino también porque han sido en alguna ocasión citadas para argumentar la procedencia de la demanda de restitución de las ganancias del deudor, según mencionamos en un punto anterior; es por ello que debemos preguntarnos si estas disposiciones admiten arribar a ese resultado.

El último tiempo nuestra jurisprudencia ha sido bastante prolífica en lo que refiere a la aplicación de las consecuencias contenidas en ambas normas, especialmente en lo dispuesto en el artículo 2316 CCCh., debido a un conjunto de demandas deducidas por la Corporación de Fomento de la Producción -Corfo- en contra de distintas empresas, en el marco del escándalo Inverlink. Es así, que en diversas causas lo que ha intentado dicha entidad es recuperar las sumas obtenidas por las demandadas, derivadas de las operaciones realizadas entre éstas e Inverlink, consistentes en contratos de compraventa con pactos de retroventa celebrados con la última, cuyo objeto fueron instrumentos financieros sustraídos a las actoras. Tales demandas se fundaron, precisamente, en que las demandadas obtuvieron ganancias derivadas de actuaciones dolosas de Inverlink. La Corte Suprema, al conocer de tales causas, razona en consideración al alcance de la norma indicada, manifestando que ella exige tres requisitos copulativos para ser aplicada a la situación del tercero -considerando vigésimo segundo-: "a. Que exista una actuación dolosa; b. que un tercero reciba provecho del dolo ajeno; c. que el que recibe el provecho no sea cómplice del dolo" ${ }^{81}$ Agrega la Corte que: "aun cuando se está en presencia de una acción

\footnotetext{
${ }^{81}$ Causa caratulada "Corporación de Fomento de la Producción con Energas S.A.", sentencia de la Corte Suprema de fecha 30 de septiembre de 2013, rol № 4871/2012. En seguida, es importante agregar que ante la excepción de prescripción opuesta por la demandada, según la cual el plazo se computaría desde la sustracción y realización de los documentos financieros con que a ella se le paga, esto es, desde la configuración del ilícito por parte de Inverlink, la Corte razona señalando que el deber de restituir tiene una "génesis compleja que involucra el acaecimiento de un acto doloso, el perjuicio causado con él a una persona, y la precepción, por parte de un tercero, de un provecho económico derivado de esa circunstancia. De ahí, que el término de prescripción debería contarse desde que el tercero percibe el beneficio".
} 
derivada de la responsabilidad extracontractual, ella no tiene la naturaleza de una acción indemnizatoria propiamente tal, ya que la obligación de restituir no está determinada por el monto de los perjuicios sufridos; tampoco tiene una relación directa con el hecho ilícito cometido, puesto que el tercero que debe restituir lo percibido no es el autor del daño. Esta obligación se genera sólo por percibirse un beneficio producto del dolo que ha sido cometido por otra persona. Así, es este provecho o utilidad el que debe ser objeto de restitución, sin perjuicio de que igualmente es necesario que se produzca un daño a la víctima, pero éste sólo opera como factor de limitación del monto máximo a restituir". El mismo razonamiento se contiene en sentencias similares ${ }^{82}$.

La doctrina nacional se ha pronunciado en variadas ocasiones sobre el artículo 2316 CCCh., especialmente para intentar determinar la naturaleza jurídica que tendría la acción que allí se contempla, oscilando entre calificarla como una modalidad de la acción indemnizatoria, o bien, sustentando un carácter restitutorio. En el conocido trabajo de Tomás Chadwick se sostiene que tanto la acción contenida en el artículo 1458, inciso segundo, como la del artículo 2316, son de naturaleza reparatoria, concordante con su postura respecto a la naturaleza delictual que tendría el dolo en todos los ámbitos en que éste se manifiesta, esto es, también en sede de incumplimiento contractual y de vicios del consentimiento. De ahí, que dicha naturaleza también se extendería a la acción que se intenta en contra del tercero que obtuvo beneficios económicos del dolo ajeno ${ }^{83}$. Una de las principales razones que arguye, es que la acción contra el tercero carecería del carácter de subsidiariedad que habitualmente se asigna a aquella que deriva del enriquecimiento injustificado o in rem ver$S O^{84}$. El profesor Domínguez Águila también se ha inclinado por la primera opinión, pues las acciones de restitución que se basan en el enriquecimiento injusto, ostentarían ciertas características que no se reunirían en la contenida en la norma en comento, entre estas, nuevamente, la subsidiariedad, en tanto el actor no debe disponer de ninguna otra para obtener la restitución, a la vez que la acción se independiza de todo daño o perjuicio, a más de prescindir de

\footnotetext{
${ }^{82}$ Como en la sentencia de fecha 12 de septiembre de 2013, causa rol № 11723/11, caratulada "Corporación de Fomento de la Producción con Inversiones Torres del Paine S.A.". Esta última adiciona que para la procedencia de la acción de restitución contenida en el artículo 2316 CCCh., se requiere la prueba de la relación de casualidad directa e inmediata entre el acto doloso cometido en perjuicio del demandante y el provecho percibido por la demandada". De igual forma se pronuncia la Corte Suprema en la reciente sentencia de fecha 16 de marzo de 2016, causa caratulada "Corporación de Fomento de la Producción con Municipalidad de Viña del Mar e Inversiones e Inmobiliaria Molin Limitada", rol No $7179 / 2015$.

${ }^{83}$ Chadwick (2009), p. 458.

${ }^{84}$ CHADWICK (2009), p. 459.
} 
la idea de dolo o culpa ${ }^{85}$. Por el contrario, la acción del artículo 2316 tendría por causa un ilícito civil específico, lo que le daría un carácter reparatorio ${ }^{86}$. Ello quedaría demostrado en el hecho de que necesariamente debe quedar establecida la configuración de un delito civil. De no haber delito civil, no sería posible intentar esta acción; misma afirmación hace respecto de la acción del artículo 1458, inciso segundo, CCCh., citando al efecto el trabajo de Tomás $\mathrm{Chadwick}^{87}$. Finalmente recuerda que atendido que acciones de esta naturaleza no se encuentran contenidas en ningún otro código, salvo en aquellos que siguieron el nuestro, ellas necesariamente debiesen proceder de Las Partidas, en que claramente se trataba de una acción indemnizatoria ${ }^{88}$.

Distinta es la línea seguida por el profesor Barros; para él, el artículo 2316 reitera la norma contenida en el artículo 1458, teniendo en ambos casos la acción una naturaleza sólo restitutoria ${ }^{89}$. De la misma opinión es Alberto Pino ${ }^{90}$. El profesor Carlos Pizarro, analizando especialmente lo dispuesto en el artículo 2316, concluye que de acuerdo a las fuentes romanas que habría seguido Bello, y puesto que en el derecho romano había tres grandes grupos de casos vinculados con el ámbito del enriquecimiento sin causa: los de enriquecimiento tradicionales; los de repetición de lo retenido sin causa; y los relacionados con lo que llega a una persona debido a un negocio determinado ${ }^{91}$; nuestro Código habría seguido la distinción y, en consecuencia, estas acciones pertenecerían a aquellas vinculadas con "los supuestos de provecho obtenido"

Pues bien, a pesar de que las disposiciones citadas no contemplan los casos que hemos denominado en términos meramente instrumentales: "incumplimiento eficiente del deudor", ya que en esos artículos no hay referencia al comportamiento de una de las partes del negocio, sino que de un tercero, igualmente podría resultar sugestivo recurrir a ellas, debido a que comparten caracteres en común: de una parte, en los dos casos, como pasaremos a señalar, hay un proceder doloso de una persona; y en segundo lugar, en ambos se

85 Domínguez (2009), pp. 218 y s.

${ }^{86}$ Domínguez (2009), p. 219.

87 Domínguez (2009), p. 221.

${ }^{88}$ Domínguez (2009), p. 226.

${ }^{89}$ Barros (2006), p. 932. Una opinión semejante se plantea en una reciente Memoria de prueba para optar al Grado de Licenciado en Ciencias Jurídicas, agregando que se trataría de una acción que deriva de las antiguas condictio del derecho romano. Díaz (2012), p. 97.

90 PINO (2016), p. 265.

91 Pizarro (2009), pp. 680 y ss.

92 Pizarro (2009), p. 681. 
reprocha el provecho o beneficio que alguien obtiene: en las situaciones que nos incumben lo obtiene el propio deudor; y en las que abarcan los artículos 1458 , inciso segundo y 2316, un tercero.

En consecuencia, se podría reconocer que debido a que el problema que abordamos no se encuentra expresamente reglamentado, se configura una laguna legal ${ }^{93}$, pudiendo recurrirse a los artículos antes citados por analogía ${ }^{94}$, pues si es admisible obtener del tercero el provecho que procede del dolo de otro ¿por qué no podría obtenerse del propio deudor? Acerquémonos a una solución en esa línea.

Aunque excede a las pretensiones de este trabajo, recordemos que la analogía es un antiguo procedimiento interpretativo que se expresaba con la fórmula: ubi eadem est legis ratio, eadem est legis dispositio ${ }^{95}$. En palabras de Geny, a diferencia de la interpretación extensiva de la ley, la analogía se dirige a "crear con su decisión o con el conjunto de su sistema, una nueva y distinta regla, fundada en la identidad de razón jurídica (ubi eadem ratio, ídem jus)". En términos similares, Betti resalta que el punto focal de las soluciones analógicas, pasan por indagar si hay alguna "correspondencia de valoración normativa"96, que justifique extender un mismo tratamiento contenido en una norma legal a un caso no contemplado por ella. De manera tal, que necesariamente se debe solucionar un caso que no se encuentra previsto por la ley; en seguida, debe existir afinidad entre el caso previsto por la ley y el caso no resuelto; y finalmente, que haya idénticas razones para solucionar el caso no resuelto de la forma que lo hace la ley análoga ${ }^{97}$. Ahora bien, no obstante la recurrencia a otras normas por esta vía parece ser bastante restrictiva, cabe recordar el llamado que, especialmente mirando al derecho privado, hace el profesor Castán

\footnotetext{
${ }^{93}$ Hablamos de laguna legal, en el sentido más habitual en el lenguaje del derecho, esto es, en tanto el ordenamiento jurídico positivo, aún el más perfecto, "deja, inevitablemente, abiertos ciertos huecos que la sola lógica es impotente a llenar, y ante los cuales, por consiguiente, la interpretación, que no puede rehusar las soluciones reclamadas por la vida, necesita, para cumplir por entero, su misión, de medios independientes de las fuentes formales". CASTÁN (2005), p. 20.

${ }^{94}$ Y que en nuestro Código Civil estaría especialmente recogido en el artículo 24. GuZmán (2011), p. 468. Con todo, Ducci pone en duda que el artículo haga referencia a casos no expresamente previstos por la ley. Ducci (1977), pp. 58 y s.

${ }^{95}$ BORDA (1951), p. 14. Aunque, como recuerda Geny, es discutible si la analogía se inserta dentro de la temática de la interpretación de la ley escrita, o si está en un lugar distinto dentro del método jurídico, sobre lo cual no entraremos, aunque este mismo autor considera que se trata de un procedimiento intermedio entre la interpretación propiamente dicha y la creación del derecho. GeNy (1925), pp. 300302.

${ }^{96}$ BetTi (2015), p. 136.

97 BORDA (1951), p. 14.
} 
Tobeñas, en cuanto la aplicación de la analogía igualmente exige del juez un rol fundamental a través de sus facultades discrecionales, a la hora de conocer un caso concreto ${ }^{98}$. Después de todo, la creatividad del juez, como proclamaba el profesor Fueyo, no sólo es una cuestión de Escuela o de teoría que se siga, sino que es la realidad práctica ${ }^{99}$. Sin embargo, nuevamente previene que en la analogía es necesario que concurran dos requisitos: existencia de laguna legal, entendiendo por tal que el caso no puede decidirse ni de acuerdo a la letra, ni de acuerdo al sentido lógico de las normas legales, aclarado por la vía de la interpretación; y que exista una igualdad jurídica esencial o eadem ratio decidendi, entre el supuesto no reglado y aquellos sí previstos por el legislador ${ }^{100}$.

Si considerásemos procedente aplicar por analogía las disposiciones mencionadas al incumplimiento eficiente, sería necesario identificar cuál es el núcleo común entre ellas y estos casos, que justifique extenderlas a estos últimos, al no estar especialmente previstos por el legislador patrio. Para alguien, dicho núcleo podría estar constituido por dos elementos centrales: la obtención de una ganancia o beneficio económico, y que dicho beneficio deriva o proviene de forma directa de un comportamiento doloso que repugna al legislador. Sin embargo, este núcleo común es solo aparente, no siendo procedente la aplicación analógica de estas disposiciones, y es que aunque se sustente que la acción concedida en estos artículos es de naturaleza restitutoria y no indemnizatoria, las propias normas exigen el cumplimiento de ciertos requisitos que han sido refrendados por la jurisprudencia, según hemos evidenciado, entre ellos, que se produzca un daño a la víctima, daño que cumple, además, la función de limitar el monto máximo a restituir ${ }^{101}$. Ambos artículos razonan sobre el supuesto de que se ha padecido un daño por la víctima, y que dicho daño es mayor al monto que se exige que sea restituido al que obtuvo provecho del dolo ajeno. Es por ello que los artículos en cuestión parten diciendo que la acción contra el autor del dolo es "por el valor total de los perjuicios" y contra quien se aprovechó de él "hasta concurrencia del provecho" -artículo 1458-, o que quien se aprovecha del dolo de un tercero "solo es obligado hasta la concurrencia del provecho"

${ }^{98}$ CASTÁn (2005), p. 310. Aunque esta prevención la hace en sentido contrario, al sustentar, citando a Geny, que si bien el juez puede recurrir a la libre investigación científica cuando se encuentra desprovisto de todo apoyo formal para solucionar un caso, previene Castán que el juez para llenar las lagunas del ordenamiento jurídico debe inspirarse en el espíritu de la propia ley y en los principios generales del sistema jurídico.

${ }^{99}$ Fueyo (1976), p. 162.

${ }^{100}$ CASTÁN (2005), p. 327.

101 Domínguez (2009), p. 225. 
-artículo 2316-. Es decir, se entiende que la víctima padeció efectivamente un daño y que dicho daño es superior al provecho experimentado por el tercero. En los casos de incumplimiento eficiente, la situación es la contraria: el beneficio experimentado por el deudor es superior a los daños padecidos por el acreedor, o este último no ha padecido daño alguno. Siendo así, no existe una completa identificación entre el núcleo de estas normas y los casos que hemos denominado de incumplimiento eficiente.

Aún más, siguiendo a Guastini en su análisis sobre la construcción jurídica y la forma de construir normas jurídicas implícitas, resulta que para aplicar por analogía uno o unos preceptos jurídicos en caso de lagunas legales, se requiere que en ambos casos -el que efectivamente contempla la norma, y el que estaría solucionado de igual manera, aunque la norma no refiera a él en forma explícita- exista una misma intención o fin: la ratio legis ${ }^{102}$. Ciertamente no parece factible sustentar que en los casos que nos ocupan el legislador pudiere perseguir el mismo fin que el propuesto con los regulados por los artículos 1458 y 2317 del CCCh. En estas normas el legislador, en forma absolutamente excepcional, permite que la víctima tenga una acción en contra de un tercero que se enriqueció por el comportamiento doloso de otro, y decimos excepcional, pues de no haber norma expresa, no habría posibilidad de dirigirse contra el tercero -a menos que a su respecto se reunieran los requisitos de la responsabilidad extracontractual- de manera tal, que aunque sea necesario que se configure responsabilidad civil respecto del hechor, en lo que refiere al tercero, los requisitos son menos rigurosos. Por el contrario, y aquí enlazamos este argumento con el contenido en el acápite anterior y el siguiente, es posible argumentar que si el legislador no estableció en forma expresa una acción de restitución de ganancias en contra del deudor, es que ello no se justifica, pues los derechos del acreedor están suficientemente resguardados: no están presentes, así, las mismas razones de equidad que son las que justifican la razón de ser de las normas en comento.

${ }^{102}$ En ese sentido, la analogía sirve para construir normas jurídicas implícitas, mediante el siguiente argumento:

“(a) El caso H2 no está regulado por ninguna norma: es decir, hay una laguna (normativa) en el derecho.

(b) Sin embargo, existe la norma N1 que regula el caso $\mathrm{H} 1$ : 'Si H1, entonces J'.

(c) El caso $\mathrm{H} 2$ es análogo al caso $\mathrm{H} 1$.

(d) Por lo tanto -conclusión- existe una norma implícita que atribuye al caso H2 la misma consecuencia jurídica que H1: 'Si H2, entonces j'. Agregando que "la identificación de una analogía entre los dos casos supone un enunciado contrafáctico del tipo: 'Si el legislador hubiera previsto el caso H2, lo habría regulado de la misma manera que $\mathrm{H}_{1}$ '. Esto, a su vez, supone la adscripción al legislador de una intención o de un fin: la así llamada ratio legis". GuASTINI (2015), p. 38. 


\subsection{Ausencia de interés del acreedor}

El acreedor carece de interés en la pretensión de restitución de las ganancias experimentadas por el deudor ${ }^{103}$. En efecto, no sólo nos parece que hay obstáculos en lo que refiere a la relación de causalidad entre la obtención de tales utilidades y el incumplimiento del deudor ${ }^{104}$, sino que aún si dicha relación existiere, resulta que el acreedor no cuenta con interés para ejercer una acción de tal naturaleza, pues el ordenamiento jurídico le proporciona los suficientes medios para afrontar el incumplimiento eficiente del deudor. Ellos son, desde luego, los remedios derivados del incumplimiento de contrato, y muy especialmente la rebaja proporcional del precio y la resolución por incumplimiento.

\section{a) La rebaja del precio como remedio de aplicación general en casos de incumplimiento eficiente}

Nos parece que la solución primaria ante un incumplimiento eficiente, en los términos expuestos en este trabajo, debería situarse en la aplicación del remedio de rebaja proporcional del precio. Por cierto que no descartamos que frente a la inobservancia del contrato, el acreedor pudiere ejercer los demás derechos que le confiere la ley, en la medida que se reúnan los requisitos para tal efecto. Así, la pretensión de cumplimiento puede ser una vía idónea para satisfacer la pretensión del acreedor, en la medida que ella sea posible y que el acreedor mantenga su interés en la misma. De consiguiente, si estamos en presencia de una prestación de naturaleza fungible, el acreedor podrá, como regla general, obtener tal cumplimiento, a menos que haya perdido interés en ella. De contrario, ello se dificulta si la prestación es no fungible. En lo que refiere a la indemnización de perjuicios, obviamente que si hay daños susceptibles de ser resarcidos, el acreedor podrá obtener la reparación. Pero, como hemos advertido, la duda que se suscita es qué ocurre si no hay daños derivados del incumplimiento o ellos son irrelevantes -por lo que no se justifique accionar en ese sentido- y el acreedor no puede o no quiere obtener el cumplimiento. En estas circunstancias, la acción de rebaja de precio parece ser una vía idónea,

${ }^{103}$ Utilizamos el término interés en forma análoga al alcance que se le confiere en el ámbito del derecho procesal, esto es, lo que mueve al demandante para deducir una acción con la finalidad de cautelarlo; es la necesidad de recurrir a la intervención del juez, para obtener un determinado bien jurídico cautelado por el oredenamiento jurídico. SiLva (2017), p. 174.

104 Barros (2009), p. 43. 
puesto que el principio que subyace en la misma es el de conmutatividad contractual ${ }^{105}$.

Como se sabe, la acción quanti minoris no sólo está prevista en el contrato de compraventa, sino también en el arrendamiento, coherente con el tratamiento llevado a cabo por el derecho romano ${ }^{106}$. Y es que aunque la acción de rebaja de precio forma parte del sistema de acciones edilicias de antigua raigambre en el derecho romano, y que en lo que toca a la compraventa son más bien propias de las ventas de cosas específicas y no de bienes genéricos ${ }^{107}$, debemos reconocer que la acción de rebaja proporcional del precio presenta una serie de ventajas, lo que ha generado no sólo la tendencia de mantenerla en los diversos ordenamientos y en el derecho uniforme, sino que de ampliar su campo de acción. Así queda en evidencia, por ejemplo, en el hecho de que luego de la reforma al derecho alemán de obligaciones, la acción permaneció casi inalterable en sede de compraventa, § 441; arrendamiento, § 536; y contrato de obra § 638 . A la vez, en la reciente reforma de 2016 al derecho de obligaciones francés, el artículo 1223 introduce la rebaja del precio con aplicación general, dentro de los derechos del acreedor ante el incumplimiento del contrato, y sin perjuicio de mantenerla en el contrato de compraventa, que no fue modificado ${ }^{108}$. Algo similar se aprecia en la Propuesta española de modernización de obligaciones y contratos, en que también se la introduce como un remedio general, en los artículos 1197 y 1198; la misma idea se mantiene en la iniciativa privada de Propuesta de Código Civil español, elaborada en forma reciente por la Asociación

\footnotetext{
${ }^{105}$ Citando a Díez Picazo, la conmutatividad del comercio jurídico se inserta en el orden público económico, pues el comercio se desarrolla eminentemente sobre la base del intercambio de bienes y servicios, intercambio que debe aspirar al mayor equilibrio posible entre las prestaciones. Dí́z PıCAzo (2007), pp. 57-58.

106 Así se aprecia en los artículos 1928 y 1930 del Código Civil. En el derecho romano la acción también se contemplaba para el contrato de arrendamiento, según consta en Instituta-Digesto, p. 971, III. De la acción estimatoria. 1. Ulpiano; Comentario al Edicto, Libro XXXII; y p. 61, 63 Ulpiano, Comentario al Edicto de los ediles curules, Libro 1. "Se ha de saber que este Edicto es aplicable únicamente a la ventas, no tan solo de esclavos, sino también de las demás cosas. Mas, parecía extraño, que nada se dijera en el Edicto respecto de los arrendamiento; pero se da esta razón; o porque nunca habían tenido los Ediles jurisdicción sobre esta materia; o porque los arrendamientos no se hacen del mismo modo que las ventas".

107 Por lo que no satisfarían las necesidades del tráfico contemporáneo, a diferencia del sistema de remedios que contiene, por ejemplo, la Convención de Viena sobre compraventa internacional de mercaderías -CISG-, que razona precisamente en relación a cosas genéricas. ZIMMERMANN (2008), p. 97; De Verda y Beamonte (2009), pp. 268-281.

${ }^{108}$ Cabe destacar que el Code no sólo innova en lo que refiere a su ámbito de aplicación, sino que además adopta un sistema extrajudicial de reducción de precio, según se lee en el inciso segundo del artículo 1223.
} 
de profesores de derecho civil ${ }^{109}$. En el derecho uniforme, por lo demás, también se le reconoce un alcance amplio de aplicación ${ }^{110}$.

Ello es comprensible cuando se evalúan los beneficios y atributos que conlleva la aplicación de esta acción; entre ellos, que su naturaleza jurídica, según hemos señalado en otro trabajo, es el de una acción de garantía que tiene por finalidad restablecer el equilibrio propio del principio de conmutatividad contractual ${ }^{111}$, lo que redunda en una modificación unilateral del contrato, readecuando el equilibrio prestacional perdido ${ }^{112}$. Por tanto, no se trata de una acción que tenga por finalidad resarcir el daño, sino que recuperar el equilibrio contractual propio de la conmutatividad de las relaciones entre privados. Siendo así, es una acción independiente de la acción de indemnización de perjuicios, como asimismo, de las demás acciones y remedios contractuales ante el incumplimiento.

Para sustentar los beneficios de la rebaja del precio, es, además, necesario reconocer que en nuestro derecho también tiene la potencialidad de ser aplicada en otros contratos, además de la compraventa y del arrendamiento. A nuestro entender, como hemos comentado en otra parte ${ }^{113}$, es posible encontrar argumentos que permiten sustentar dicha tesis. Sin duda, tal como se ha hecho con otras instituciones del derecho contemporáneo de contratos $-y$ reconociendo el gran rol que ha tenido la doctrina como fuente del derecho en estos aspectosresulta que las normas contenidas en nuestro Código Civil poseen la suficiente plasticidad para adoptar esa línea argumental. Así, aunque el código no ha sido objeto de grandes modificaciones en el libro IV, lo cierto es que disposiciones tales como los artículos 1546 y 1569 , entre otras, permiten afirmar que las nociones que conforman el binomio cumplimiento/incumplimiento, son lo

109 Así se evidencia de lo dispuesto en los artículos 518-9, 518-10 y 518-11 de la Propuesta. En efecto, el artículo 518-9 establece: "La parte que recibe una prestación no conforme con el contrato puede aceptarla y reducir el precio en proporción a la diferencia de valor que la prestación tiene en el momento en que se realiza y el que tendría en ese momento si hubiera sido conforme con el contrato". Propuesta de Código Civil (2016), p. 126.

110 Además de estar contemplada en la CISG, los PECL le reconocen un alcance amplio en el art. 9:401, pues la reducción refiere a una contraprestación de carácter dineraria, que tenía que llevar a cabo la parte perjudicada por el incumplimiento de la otra; y también como remedio general se contiene en el Draf Common Frame of Reference, cfr. III. 3:601. En el orden latinoamericano, el artículo 96 de los PLDC también asigna a la reducción del precio un alcance general. De manera tal que claramente se visualiza esta propensión a conferirle un ámbito amplio de aplicación, más allá de los contratos en que tradicionalmente la acción quanti minoris era regulada.

111 PRADO (2015), p. 630.

112 De Verda y Beamonte (2009), p. 264; Bercovitz (1969), p. 789.

113 PRADO (2013), p. 382. 
suficientemente dúctiles como para admitir una concepción neutra de dicho incumplimiento, que posibilita al acreedor insatisfecho optar por la acción o remedio que le parezca más conveniente a sus intereses. En seguida, las mismas normas contenidas en el contrato de compraventa y de arrendamiento que regulan la acción quanti minoris, pueden ser reinterpretadas para ser aplicadas a otros contratos que generen obligaciones de dar y de simple entrega, atendido el carácter paradigmático de dichos contratos. En lo que respecta a un contrato cuya obligación incumplida sea de hacer, y que tenga una contraprestación susceptible de ser rebajada, es posible sustentar una rebaja del precio, por ejemplo, a partir de lo dispuesto en el art. 2158, inciso final. Si el mandante se puede dispensar de cumplir con sus obligaciones para con el mandatario en caso que no ha tenido éxito en su gestión, o se pudo desempeñar a menor costo, en la medida que pruebe la culpa de dicho mandatario, y resulta que entre esas obligaciones está el pago de la remuneración al mandatario; pues tal remuneración se podría rebajar si el incumplimiento del mandatario ha sido imperfecto ${ }^{114}$.

Por consiguiente, bastaría que se cumplan los siguientes requisitos para que la acción sea posible de ser entablada: un contrato con una contraprestación susceptible de ser reducida y que la prestación o prestaciones de la contraparte, cualquiera sea su naturaleza, se cumplan en forma imperfecta, tanto en contratos típicos -como un mandato remunerado-, como en caso de contratos atípicos.

En síntesis, si el incumplimiento eficiente del deudor es de naturaleza imperfecta, pero el acreedor prefiere mantener vigente el contrato, es factible que mediante la reducción del precio, el deudor obtenga directamente del contrato sólo el beneficio equivalente al cumplimiento del mismo, aunque su incumplimiento le haya generado otras ganancias.

\section{b) La resolución por incumplimiento doloso}

Como se ha afirmado en forma reiterada por la doctrina más autorizada ${ }^{115}$, la concepción que hoy se impone del incumplimiento contractual es su naturaleza neutra. Ello también se proyecta en los requisitos del remedio resolutorio, en que, como se sabe, no se exige culpa del deudor, bastando que dicho incumplimiento tenga un carácter de esencial, como se lee en la CISG y en los demás instrumentos del derecho uniforme. Así, en el artículo 7.3.1 de los Principios Unidroit; en el artículo 9:301 de los PECL; en el artículo III.- 3:502 del MCR; artículo 1199 del Proyecto de Modernización español en materia de

\footnotetext{
114 Prado (2013), p. 383.

115 Morales (2009), p. 207; Morales (2014), p. 89; Vidal (2006), p. 439.
} 
obligaciones y contratos; artículo 518-13 del Proyecto de Código Civil español, Libros V y VI, de los profesores de derecho civil de ese país; artículo 97 de los PLDC. Con todo, hacemos presente que en la reciente reforma al Code en materia de derecho de obligaciones, que entró en vigencia el 1 de octubre de 2016, no se habla de incumplimiento esencial, sino de un incumplimiento suficientemente grave en el artículo 1224.

Pues bien, si la noción de incumplimiento esencial es, en general, acorde a tal concepción neutra de incumplimiento del derecho contemporáneo de contrato y en tanto supuesto de todo remedio: ¿Cuál es el rol que puede desempeñar el incumplimiento doloso en este caso? El planteamiento surge debido a que algunos de estos mismos instrumentos de derecho uniforme, incluyen como una de las hipótesis de incumplimiento esencial, aquel incumplimiento de naturaleza intencional, como señalan el mismo artículo 7.3.1,2) letra c) de los Principios Unidroit, que alude al caso en que "el incumplimiento fue intencionado y dé motivos a la parte perjudicada para entender que ya no podrá contar en el futuro con el cumplimiento de la otra parte"; o el artículo 8:103, letra c) de los PECL, que expresa que es esencial "cuando el incumplimiento sea intencionado y dé motivos a la parte perjudicada para entender que ya no podrá contar en el futuro con el cumplimiento de la otra parte"; el artículo III: 3:502, 2, letra b), del MCR, que indica "el incumplimiento es deliberado o imprudente y da al acreedor motivos para creer que no se puede confiar en el futuro cumplimiento del deudor"; y "el incumplimiento es doloso", artículo 87, letra b), de los PLDC.

De modo tal, que cabe preguntarse si en estas disposiciones lo que aparece es una expresa referencia al incumplimiento doloso. De ser afirmativa la respuesta, estaríamos en otro ámbito en que el dolo en el contrato tiene relevancia. El problema, es que no hay mayores análisis sobre este supuesto de incumplimiento esencial, ni en el derecho foráneo, ni mucho menos en nuestro país, salvo contadas excepciones ${ }^{116}$.

Con todo, es claro que el dolo en el incumplimiento contractual adquiere relevancia en sede de incumplimiento resolutorio, permitiendo al acreedor desligarse del contrato, aunque el incumplimiento mirado objetivamente, no tenga la gravedad para ello. En efecto, en estos casos, la gravedad viene dada por el comportamiento desplegado por el deudor, en tanto ha creado en el acreedor la desconfianza sobre si, finalmente, cumplirá o no. La consideración del dolo del deudor para estos efectos, no implica una vuelta a una concepción subjetiva del incumplimiento resolutorio: se mantiene la concepción neutra del mismo, que se desliga de la idea de que la resolución constituye una sanción para el

${ }^{116}$ VIDAL (2009), pp. 243-244. 
deudor; persiste, así, el hecho de que la resolución mira al interés que tiene el acreedor de desvincularse del contrato, lo que ocurre, es que acá el motivo es esa falta de confianza originada por el propio deudor. Por consiguiente, el dolo faculta al acreedor para igualmente resolver el contrato, sea porque el deudor ya incumplió intencionalmente, o porque su comportamiento doloso da motivos para desconfiar que cumpliráa ${ }^{117}$.

Si se vincula, entonces, esta idea con la noción de incumplimiento eficiente, resulta que otro escenario posible es que aunque ese incumplimiento del deudor no revista, en principio, una entidad notoria desde el punto de vista objetivo, atendido que el incumplimiento eficiente constituye una modalidad que puede revestir el incumplimiento doloso, ello posibilitaría al acreedor desvincularse del contrato.

De ahí que el dolo con que el deudor incumple el contrato es un elemento central que posibilita perfilar el incumplimiento eficiente. Para sostener esta afirmación, es necesario explicitar en qué sentido hemos de entender el dolo para estos efectos. Simplificando el análisis, sabemos que tanto la doctrina nacional como foránea se ha decantado en, al menos, dos sentidos fundamentales: calificar como incumplimiento doloso todo incumplimiento voluntario o intencional; o bien, que el dolo en el contrato necesariamente se manifiesta en un incumplimiento intencional o voluntario que busca ocasionar daño al acreedor ${ }^{118}$.

Una buena parte de los autores nacionales se han inclinado por la primera postura, afirmándose, por ejemplo, que el dolo contractual importa la "intención principal de dañar o simplemente aspirando a un beneficio propio y aceptando como inevitable (aunque no querido directamente) el daño ajeno"119. Así

${ }^{117}$ En ese orden, hacemos presente que concordamos con lo que postula el profesor Contardo, en cuanto a que sería factible en casos calificados resolver el contrato en forma anticipada, si existe la certeza que el deudor no cumplirá. CONTARDO (2013), p. 273.

${ }^{118}$ Sucintamente, la doctrina foránea distingue dos corrientes de pensamiento; la primera supone adoptar una concepción restringida de dolo, que implica un propósito consciente y deliberado en el incumplimiento, pero además, la intención de embaucar o engañar a otro, como es la seguida por Dumoulin, y más recientemente por Gómez Pomar. Fuentes (2009), p. 426; Gómez (2002), p. 223; y de otra parte, una más amplia de dolo en el incumplimiento del contrato, que implica un incumplimiento deliberado y consciente, en que el elemento intencional tendría como relevancia el distinguir a dicho dolo de la culpa contractual; de ahí, que el dolo en sede contractual constituiría la regla general, pues el dolo se explicaría por razones económicas, más que sicológicas. Fuentes (2009), p. 432; CarRasCo (1989), p. 445.

${ }^{119}$ Corral (2010), p. 199. Cita Corral al pensamiento de Fernando Gómez Pomar, para quien el dolo necesariamente implica una intención injuriosa y no sólo un incumplimiento voluntario, y no obstante resalta que podría ser aconsejable restringir el alcance del dolo en tal sentido, considera que no sería ajustado al texto de nuestra norma. Rodríguez Grez, postula que el dolo en el contrato supone la reu- 
Fueyo, que en línea similar considera que el dolo en sede contractual importa que el incumplimiento es previsto y querido por el deudor, por lo que estaría en sus manos cumplir o no cumplir, prefiriendo la segunda alternativa ${ }^{120}$; dicha conciencia no sólo requiere que el deudor tenga la intención de dañar al acreedor, lo que es más bien excepcional, sino que basta con la conciencia de dañar al deudor ${ }^{121}$.

Empero, hay que resaltar que en algunos autores nacionales no queda claro si exigen para la configuración del incumplimiento doloso la efectiva intención de dañar al acreedor, o la sola conciencia del daño que podría causarse ${ }^{122}$.

En la otra línea, es especialmente relevante la opinión seguida por Chadwick. Como éste señala, la mayoría de los deudores se dan cuenta tanto del hecho de que dejan de cumplir sus obligaciones, como de las consecuencias que de ello derivan para sus acreedores, ello, sin embargo, no importa un incumplimiento doloso, incluso más, agrega que no es "suficiente la mera representación o previsión de las consecuencias que trae consigo el incumplimiento de las obligaciones. Para que exista dolo, no basta que el deudor tenga plena conciencia de violar sus obligaciones"123, necesariamente debe existir la intención de injuriar al acreedor; entonces, es la finalidad que el deudor persigue con su incumplimiento lo que permite calificar al mismo de doloso o culposo ${ }^{124}$. Esta

nión de tres condiciones: una conducta autodeterminada; la conciencia de ilicitud de dicha conducta; y la convicción de que ella provocará un daño. RODRíGuez (2005), p. 149. En relación con el tercer elemento, agrega que el denominado dolo eventual quedaría comprendido en la noción de dolo del artículo 44 CCCh. en sede de incumplimiento contractual, adicionando que es poco probable que un deudor incumpla con el solo propósito de causar daño al acreedor, por lo que en lo que refiere al daño susceptible de ser provocado con su incumplimiento, es decir, si el dolo eventual se caracteriza porque el deudor representa el resultado de su acción como posible, pero no como cierto, esto supone que no habría por parte del deudor una certeza respecto a que dicho daño se producirá, sino solamente que es probable que el daño se produzca, de manera tal que la intención positiva de causar daño del artículo 44 CCCh. cubriría también este caso, pues aunque el daño no es cierto, sino sólo probable, igual el deudor estuvo en posición de evitarlo y no lo hizo, p. 153.

${ }^{120}$ FUEYO (1991), p. 418.

${ }^{121}$ FUEYO (1991), p. 419.

122 Así, Troncoso (2007), p. 203; SaAvedra (1994), p. 226; Meza (1994), p. 265. En el caso de este último, por ejemplo, solo menciona que sería "toda maquinación fraudulenta destinada a eludir el incumplimiento de una obligación".

123 Chadwick (2009), p. 471.

${ }^{124}$ Chadwick (2009), pp. 471 y s. Por lo demás, la opinión del autor es coherente con el origen histórico del dolo. Especialmente resalta el alcance de la actio doli en el derecho romano, que era también aplicable al dolo en materia contractual, y que tiene antecedentes inmediatos en acciones destinadas a castigar el dolo en ciertos contratos, como en el depósito o en la sociedad si el contratante incurrió en comportamientos dolosos a fin de perjudicar al otro contratante, o para beneficiarse de sus expensas; así la sanción del dolo en la ejecución del contrato tuvo como antecedente la actio doli, pp. 348 y s. 
postura es coherente con la tesis que Chadwick sustenta, en orden a que el dolo siempre tiene una naturaleza jurídica delictual y que emanaría directamente del tenor y de la ubicación del artículo 44 CCCh., de ahí que la obligación de indemnizar en este último caso deriva de un hecho nuevo que sería precisamente la comisión de un delito civil que se realiza al interior del contrato ${ }^{125}$.

Si se sigue la opinión de la mayor parte de nuestros autores y se postula que el dolo en sede contractual es la sola conciencia y voluntariedad del incumplimiento, pues bien, la mayoría de los incumplimientos se calificarían de dolosos, en circunstancias que el dolo en el contrato es del todo excepcional: esa es la razón por la cual el artículo 1558 CCCh. se ocupa de él en forma especial, a más de tratarse de una postura mucho más cercana al tenor literal de nuestro artículo $44^{126}$. Por ello es que nos inclinamos por conferir al dolo contractual un alcance más restrictivo, el dolo en el incumplimiento del contrato no está constituido por el solo incumplimiento voluntario de la obligación, concordando con la opinión de profesor Morales Moreno, "incumplimiento doloso no es cualquier incumplimiento voluntario; por ejemplo, el retraso intencionado en el cumplimiento. Si así fuera, tendríamos que calificar de dolosos a muchos incumplimientos no fortuitos (art. 1105 CC.), lo que distorsionaría enormemente el sistema de responsabilidad contractual. El carácter voluntario del incumplimiento no lo convierte, necesariamente, en doloso. Ni siquiera cuando media una conducta "deliberadamente rebelde del deudor", tomada en cuenta por la jurisprudencia del TS para permitir la resolución del contrato".

El supuesto de dolo previsto en el art. 1107 II podemos definirlo así: Es un acto de incumplimiento del contrato, causante de daños a bienes o intereses del acreedor que se sitúan más allá del interés protegido por el contrato (art. 1107 I: fin de protección del contrato), y que por la intención del sujeto, que directamente pretende causar un daño al otro contratante, o por la propia antijuridicidad del acto (acto contrario a una norma o las exigencias de la buena fe) justifica una imputación de responsabilidad al deudor fundada en la ilicitud de su conducta y no exclusivamente en el hecho del incumplimiento"127.

\footnotetext{
125 Chadwick (2009), p. 470.

${ }^{126}$ Cabe observar que Abeliuk sigue una postura semejante, en tanto acá la intención del dolo del deudor es precisamente dañar al acreedor, aunque lamentablemente no proporciona mayores argumentos, como no sea el tenor literal del artículo 44 CCCh. AвELIuk (2009), p. 734.

127 Morales (2010), p. 175. Casos como los que cita el profesor Morales Moreno, de una compraventa genérica en que el vendedor conoce que el objeto entregado puede causar daños a los compradores -como el recordado caso de los laboratorios nacionales en el bullado caso de la leche ADN mal elaborada-; o el caso de un contrato en que existía el compromiso de celebrar un mutuo dinerario, que el prestamista deja de cumplir, con la intención de evitar que la contraparte realizara la inversión
} 
En este punto, interesa traer a colación las palabras del profesor Jorge Baraona, en su ya clásico trabajo sobre la responsabilidad contractual y los factores de imputación de daños, en torno al alcance que tendría el dolo en la infracción del contrato. Para él, el dolo supone una infracción voluntaria al contrato, a diferencia de la falta de diligencia en que el incumplimiento no sería querido por el deudor aunque no ha hecho lo posible por evitarlo; y agrega que en lo que refiere a la asimilación con la culpa grave, el elemento intencional del dolo sólo cobraría relevancia en caso que el comportamiento del deudor no sea posible de ser calificado como gravemente negligente, pues de lo contrario bastaría este comportamiento para que la responsabilidad se vea aumentada ${ }^{128}$. Siendo así, en la determinación de los daños resarcibles para el caso que el acreedor deduzca una acción indemnizatoria sería, en principio, indiferente perfilar el incumplimiento doloso, pues basta que se acredite culpa grave, a menos que no sea posible que esta última se configure.

Con todo, nos parece que de afirmarse que en casos de comportamiento doloso, como el que se manifiesta en un incumplimiento eficiente, es factible obtener la resolución del contrato, este sería, sin duda, otro ámbito en que el elemento intencional cobraría importancia. De ahí que no es indiferente adoptar cualquier postura acerca del sentido y alcance del dolo contractual, pues aunque en sede de indemización de perjuicios el incumplimiento doloso ha perdido relevancia práctica, hay aquí otro ámbito en que el dolo es relevante para el acreedor, por ello, nos parece acertado sostener que el incumplimiento doloso supone tanto la intención de causar daño al acreedor como, asimismo, los incumplimientos en que se denota una conducta particularmente fraudulenta, que implique conocimiento y voluntariedad de todas las eventuales consecuencias derivadas del mismo, aunque su finalidad principal sea la obtención de beneficios. De ahí, que en todos los casos de incumplimiento eficiente estaremos en presencia de un incumplimiento doloso, por ejemplo, porque desde antes de la celebración del contrato incumplido, el deudor negociaba paralelamente, celebrando luego ambos contratos: el primero en condiciones menos favorables, por lo que decide cumplir el segundo en desmedro del primero; ya, porque a pesar de que no pretende cumplir el contrato, al estar negociando con el segundo contratante, se vale de artilugios para hacer creer a su primer acreedor que cumplirá, aunque sea en forma retardada, entre otras conductas.

prevista, p. 176. SÁNCHEZ (2011), p. 468. Coherente con esta opinión, es que el profesor Morales Moreno se traslada en un sentido análogo al comportamiento doloso del vendedor. Morales (1982), p. 635.

${ }^{128}$ BARAONA (1997), p. 173. 


\section{Conclusiones}

1.- El alcance del incumplimiento eficiente es amplio, toda vez que lo que busca es el diseño de instrumentos jurídicos que posibiliten maximizar los recursos y obtener resultados eficientes ante un incumplimiento contractual. Con todo, en este trabajo se habla de incumplimiento eficiente en forma instrumental, con la finalidad de identificar a un grupo de casos al que se circunscribe este ensayo, referido a aquellos en que el deudor no cumple porque de dicho incumplimiento obtendrá mayores beneficios, en contraste con el cumplimiento de la convención, ya sea porque del mismo no resultarán daños al acreedor, o ellos serán muy menores. Este resultado se producirá, sobre todo, en las situaciones en que el deudor celebra otro contrato con un tercero, en términos más favorables.

2.- La pregunta central se sitúa en determinar si conforme al ordenamiento jurídico nacional el acreedor está facultado para obtener que el deudor le entregue las mayores utilidades derivadas del incumplimiento eficiente, o si, por el contrario, no hay argumentos dogmáticos que permitan sustentar una solución de esa naturaleza.

3.- En el derecho foráneo es del todo discutible sustentar la procedencia de la restitución de las ganancias derivadas del incumplimiento eficiente del deudor; lo mismo puede afirmarse en el marco del derecho uniforme. En el derecho nacional, se trata de una cuestión escasamente abordada, aunque quienes lo han analizado postulan que una posibilidad es valerse de lo dispuesto en los artículos 1458, inciso segundo, y 2316 del CCCh.

4.- En nuestra opinión, no es posible sustentar que el deudor ha de entregar al acreedor los mayores beneficios o ganancias derivados de su incumplimiento eficiente, en tanto no hay argumentos dogmáticos al efecto; así, no es procedente aplicar analógicamente los artículos 1458, inciso segundo, y 2316 del CCCh. A la vez, el acreedor carece de interés para obtener esos provechos, atendido que cuenta con los remedios por incumplimiento, entre los cuales resaltan la rebaja proporcional del precio y la resolución por incumplimiento. En el caso del remedio resolutorio, sostenemos que el incumplimiento eficiente es una modalidad del incumplimiento doloso, de manera tal que dicho dolo permite al acreedor desligarse del contrato producto de la pérdida de confianza en la contraparte que ha incumplido eficientemente.

\section{BiBLIOGRAFÍA CITADA}

Abeliuk Manasevich, René (2009): Las obligaciones (Santiago, Editorial Jurídica de Chile), Tomo II. 
AlCALDE SILVA, Jaime (2009): “El commodum repraesentationis del artículo 1677 del Código Civil", en: Estudios de Derecho Civil IV (Santiago, Editorial Legal Publishing), pp. 487-507.

Asociación de Profesores de Derecho Civil (2016): Propuesta de Código Civil. Libros quinto y sexto (Valencia, Tirant lo Blanch).

Baraona GonzÁlez, Jorge (1997): "Responsabilidad contractual y factores de imputación de daños: apuntes para una relectura en clave objetiva", en: Revista Chilena de Derecho (Vol. 24, № 1), pp. 151-177.

Barcia Lehmann, Rodrigo (2010): Lecciones de Derecho Civil Chileno. De la teoría de las obligaciones (Santiago, Editorial Jurídica de Chile), Tomo III.

BarRos Bourie, Enrique (2006): Tratado de responsabilidad extracontractual (Santiago, Editorial Jurídica de Chile).

(2009): “Restitución de ganancias por intromisión en derecho ajeno, por incumplimiento contractual y por ilícito extracontractual", en: Derecho de daños (Madrid, Fundación Coloquio Jurídico Europeo), pp. 11-77.

Basozábal Arrué, Xabier (1997): "Método triple de cómputo del daño: la indemnización del lucro cesante en las leyes de protección industrial e intelectual", en: Anuario de Derecho Civil (fascículo III), pp. 1263-1299.

(1998): Enriquecimiento injustificado por intromisión en derecho ajeno (Madrid, Civitas).

(2018): "Enriquecimiento injusto comparado: una aproximación al Derecho inglés de restituciones, en: Anuario de Derecho Civil (fascículo I), pp. 14-78.

BerCovitz y Rodríguez CANO, Rodrigo (1969): "La naturaleza de las acciones redhibitoria y estimatoria en la compraventa", en: Anuario de derecho civil (fascículo IV), pp. 777-837.

BetTı, Emilio (2015): Teoría de la interpretación jurídica (Traduce Alejandro Vergara Blanco, Santiago, Ediciones Universidad Católica de Chile).

BIRKS, Peter (2014): Unjust Enrichment (Oxford, University Press), $2^{\text {a }}$ edición.

BORDA, Guillermo A. (1951): Reglas prácticas para la interpretación de la ley civil (Madrid, Instituto Editorial Reus).

CampbelL, David y HarRIS, Donald (2002): "In defence of breach: a critique of restitution and the performance interest", en: Legal Studies (22), pp. 208-237.

Cano Martínez de Velasco, José Ignacio (2007): El daño por intromisión (Madrid, Editorial Dilex S.L.).

Carrasco Perera, Ángel (1988): "Restitución de provechos II", en: Anuario de Derecho Civil (XLI, fascículo I), pp. 5-151. 
(1989): "Comentarios al artículo 1102", en: Comentarios al Código Civil y Compilaciones forales (Madrid, Editorial Revista de Derecho Privado).

CASTÁn TOBEÑAs, José (2005): Teoría de la aplicación e investigación del derecho (Madrid, Editorial Reus S.A.).

Contardo González, Juan Ignacio (2013): "La resolución por anticipación o por incumplimiento previsible. Intento de construcción a partir de los artículos 1826 del Código Civil y 147 del Código de Comercio", en: Estudios de Derecho Civil VIII (Santiago, Legal Publishing Thomson Reuters), pp. 265-280.

Cooter, R. y Ulen, T. (2016): Law and Economics (Boston, Addison-Wesley), $6^{\text {a }}$ edición.

Corral Talciani, Hernán (2010): Contratos y daños por incumplimiento (Santiago, Abeledo Perrot, Legal Publishing).

Correa Ferrer, Pablo y García Mekis, Benjamín (2016): “Incumplimientos en el contrato de construcción a suma alzada en Chile. Criterios jurisprudenciales en relación al aumento del costo y la extensión del plazo de las obras", en: Actualidad Jurídica Uría Menéndez (No 42), pp. 53-62.

ChaDWick, Tomás (2009): "De la naturaleza jurídica del dolo", en: Doctrinas esenciales. Derecho Civil. Responsabilidad extracontractual (Santiago, Editorial Jurídica de Chile), pp. 65-107.

Dannemann, Gerhard (2009): The German Law of unjustified enrichment and restitution: A comparative Introduction (Oxford, Oxford University).

De la Maza Gazmuri, Íñigo; Pizarro Wilson, Carlos, y Vidal Olivares, Carlos (2017): Los principios latinoamericanos de Derecho de contratos (Madrid, Imprenta Nacional de la Agencia Estatal Boletín Oficial del Estado).

De Verda y Beamonte, José (2009): Saneamiento por vicios ocultos. Las acciones edilicias (Navarra, Aranzadi Thomson Reuters).

Díaz García Huidobro, María Florencia (2012): Naturaleza jurídica de la acción por provecho obtenido del dolo ajeno que conceden los artículos 1458 y 2316 del Código Civil (Santiago, Memoria de Prueba para optar al Grado de Licenciado en Ciencias Jurídicas y Sociales de la Universidad de Chile).

Díez Picazo, luis y De la Cámara Álvarez, Manuel (1988): Dos estudios sobre el enriquecimiento sin causa (Madrid, Editorial Civitas S.A.).

Díez Picazo, luis; Roca Trías, Encarna, y Morales Moreno, Antonio Manuel (2002): Los principios del Derecho europeo de contratos (Madrid, Civitas).

Díez Picazo, Luis (2007): "Commodum ex negotiatione", en: Anuario de Derecho Civil (LX, fascículo IV), pp. 1601-1617. 
(2007): Fundamentos del derecho civil patrimonial I. Introducción. Teoría del contrato (Navarra: Civitas-Thomson Reuters).

(2007): "Indemnización de daños y restitución de enriquecimientos", en: Anales de la Real Academia de Jurisprudencia y Legislación (Madrid, Editorial Dykison), pp 237-254.

(2011): Fundamentos del derecho civil patrimonial. La responsabilidad civil extrapatrimonial (Navarra, Civitas Thomson Reuters).

Domínguez Benavente, Ramón; Domínguez Águila, Ramón, y Domínguez Hidalgo, Carmen (1996): "Comentarios de Jurisprudencia", en: Revista de Derecho Universidad de Concepción (№ 199, año LXIV, enero-junio), pp. 179-185.

Domínguez Águila, Ramón (2009): "Sobre el artículo 2316 inciso segundo del Código Civil y la acción contra el que recibe provecho del dolo ajeno", en: Revista de Derecho Universidad de Concepción (№ 225-226, año LXXVII, enero-diciembre), pp. 217-230.

Ducci Claro, Carlos (1977): Interpretación jurídica (Santiago, Editorial Jurídica de Chile).

Dyson, Andrew; GoudKamp, James, y WiLmot-SMith, Frederyck (2016): "Questions and themes", en: Defences in unjust enrichment (Oxford, Hart Publishing Bloomsbury), pp. 1-25.

Fenor Picón, Nieves (2011): “La modernización del régimen del incumplimiento del contrato: propuestas de la Comisión General de Codificación. Parte segunda, los remedios del incumplimiento", en: Anuario de Derecho Civil (2011), pp. 1481-1674.

Fuentes Guíñez, Rodrigo (2009): La extensión del daño contractual (Madrid, La Ley).

Fuero Laneri, Fernando (1976): Interpretación y juez (Santiago, Ediciones Universidad de Chile y Centro de Estudios "Ratio luris").

(1991): Cumplimiento e incumplimiento de las obligaciones (Santiago, Editorial Jurídica de Chile).

Gatica Pacheco, Sergio (1959): Aspectos de la indemnización de perjuicios por incumplimiento del contrato (Santiago, Editorial Jurídica de Chile).

GaVIRIA GIL, Juan Antonio (2015): "Sobre la aplicación de la teoría del incumplimiento eficiente de contratos en el derecho colombiano", en: Revista de Derecho y Economía (№ 44, julio-diciembre), pp. 37-57.

GeNY, Francois (1925): Método de interpretación y fuentes en derecho privado positivo (Madrid, Editorial Reus S.A.).

Gómez Pomar, Fernando (2002): Previsión de daños, incumplimiento e indemnización (Madrid, Civitas A. Thomson Company). 
GonzÁlez, Jesús (1994): "El análisis económico del derecho: algunas cuestiones sobre su justificación", en: Doxa (15-16), pp. 929-943.

GuastinI, Riccardo (2015): "Interpretación y construcción jurídica", en Isonomía ( No 43, octubre), pp. 11-48.

GuZMÁn Brito, Alejandro (2011): Codificación del derecho civil e interpretación de las leyes. Las normas sobre interpretación de las leyes en los principales Códigos civiles europeo-occidentales y americanos emitidos hasta fines del siglo XIX (Madrid, lustel Portal Derecho S.A.).

IBÁÑNEZ, Javier (2011): Análisis económico del derecho. Método, investigación y práctica jurídica (Barcelona, Bosch Editor).

JIMÉMEZ, Felipe (2017): "Una crítica a la idea de incumplimiento eficiente desde el derecho de los contratos", en: Revista Chilena de Derecho Privado (No 29), pp. 99-136.

Kahneman, Daniel y TVersky, Amos (2000): Choices, Values and Frames (Cambridge, University Press).

KLAss, Gregory (2014): "Efficient breach", en: Philosophical Foundations of Contract Law (Oxford, University Press), pp. 362-387.

LIAO, W. (2015): The application of the theory of efficient breach in contract law (Cambridge, Intersentia Publishing Ltd.).

Markovits, Daniel y Schwartz, Alan (2011): "The myth of efficient breach: new defenses of the expectation interest", en: Yale Law School Legal Scholarship repository, pp. 1940-2008.

Martínez, Carlos (2014): "Insuficiencias del análisis económico del derecho como base para una teoría de la adjudicación", en: Revista Chilena de Derecho (Volumen 14, $\mathrm{N}^{\circ}$ 3), pp. 925-955.

Medina CRespo, Mariano (2015): La compensación del beneficio obtenido a partir del daño padecido (Barcelona, Bosch).

Meza Barros, Ramón (1994): Manual de Derecho Civil. De las obligaciones (Santiago, Editorial Jurídica de Chile).

Momberg Uribe, Rodrigo (2017): "Restitución de ganancias por incumplimiento contractual", en: Estudios de Derecho Civil XII (Santiago, Thomson Reuters), pp. 419-432.

Morales Moreno, Antonio Manuel (1982): "El dolo como criterio de imputación de responsabilidad al vendedor por los defectos de la cosa", en: Anuario de Derecho Civil (1982, fasc. III), pp. 591-684. 
(2009): "Problemas que plantea la unificación del concepto de incumplimiento del contrato. Respuesta a Enrique Barros", en: Derecho de daños (Madrid, Fundación Coloquio Jurídico Europeo), pp. 193-221.

(2010): Incumplimiento y lucro cesante (Madrid, Ministerio de Ciencia e Innovación).

(2014): "Claves de la modernización del derecho de contratos", en: Estudios de Derecho de Contratos. Formación, cumplimiento e incumplimiento (Santiago, Legal Publishing, Thomson Reuters), pp. 15-123.

(2017): “Tradición e innovación en la nueva regulación del enriquecimiento injustificado del Código Civil francés", en: Estudios Jurídicos. Liber Amicorum en honor a Jorge Caffarena (Madrid, Colegio de Registradores de la Propiedad y Mercantiles), pp. 583-611.

Orozco Muñoz, Martín (2015): El enriquecimiento injustificado (Navarra, Thomson Reuters Aranzadi).

Pantaleón Prieto, Fernando (1991): "El sistema de responsabilidad contractual", en: Anuario de Derecho Civil (fasc. III), pp. 1019-1091.

(1993): "Las nuevas bases de la responsabilidad contractual", en: Anuario de Derecho Civil (fasc. IV), pp. 1719-1745.

Peñallillo Arévalo, Daniel (1996): “El enriquecimiento sin causa. Principio de derecho y fuente de obligaciones, en: Revista de Derecho Universidad de Concepción ( $N^{\circ} 200$, año LXIV), pp. 8-40.

PINO EMHART, Alberto (2016): "La restitución de ganancias ilícitas y la acción de provecho por dolo ajeno", en: Revista lus et Praxis (año 22, № 1), pp. 227-270.

PizarRo Wilson, Carlos (2009): "La acción de restitución por provecho de dolo ajeno", en: Estudios de Derecho Civil IV (Santiago, Legal Publishing), pp. 679-688.

Posner, Richard (2007): El análisis económico del derecho (México D.F., Fondo de Cultura Económica).

Prado López, Pamela (2013): "La rebaja del precio como remedio contractual en el derecho chileno: una aproximación", en: Estudios de Derecho Civil VIII (Santiago, Legal Publishing, Thomson Reuters), pp. 369-383.

(2015): "La cuantificación de la rebaja del precio en la acción quanti minoris", en: Revista lus et Praxis (año 21, № 1), pp. 617-650.

(2016): "El dolo causal y su repercusión en el contrato", en: Revista lus et Praxis (año 22, № 2), pp. 425-456. 
Rodríguez Grez, Pablo (2015): Responsabilidad contractual (Santiago, Editorial Jurídica de Chile).

Saavedra Galleguillos, Francisco (1994): Teoría del consentimiento (Santiago, Editorial Jurídica ConoSur).

SÁnchez Ruiz de Valdivia, Inmaculada (2011): "La moderna regulación de la indemnización de daños y perjuicios por incumplimiento contractual en el nuevo derecho de la contratación: el triángulo de las Bermudas", en: Derecho privado europeo y modernización del Derecho contractual en España (Barcelona, Atelier Libros Jurídicos), pp. 448-482.

Segura Riveiro, Francisco (2007): "El interés indemnizable en las hipótesis de responsabilidad precontractual", en: Estudios de Derecho Civil II (Santiago, Editorial LexisNexis), pp. 345-362.

SILVA HaNISCH, Maximiliano (2017): "La terminación anticipada del proceso por la desaparición sobrevenida del interés en el proceso civil chileno", en: Revista de Derecho de la Pontificia Universidad Católica de Valparaíso (XLVIII, $1^{\text {er }}$ semestre), pp. 167-198.

Sutherland Borja, Thomas (2014): "Condiciones imprevistas en los contratos de construcción a suma alzada y su aplicación al sitio de las obras", en: Revista Chilena de Derecho Privado (№ 22, julio), pp. 161-195.

Troncoso Larronde, Hernán (2007): De las obligaciones (Santiago, LexisNexis).

ZimmermanN, Reinhard (2000): Estudios de derecho privado europeo (Madrid, Civitas Ediciones S.L.).

(2008): El nuevo derecho alemán de obligaciones. Un análisis desde la Historia y el Derecho comparado (Traduce Esther Arroyo i Amayuelas, Barcelona, Bosch).

Zurita MARTIN, Isabel (2015): "Indemnización por daños y perjuicios e intereses", en: Antoni Vaquer Aloy, Esteve Bosch Capdevila y María Paz Sánchez González, editores, El derecho común europeo de la compraventa y la modernización del derecho de contratos (Barcelona, Atelier), pp. 671-697.

Vidal Olivares, Álvaro (2006): "El incumplimiento contractual y los remedios de que dispone el acreedor en la compraventa internacional", en: Revista Chilena de Derecho (Volumen 33, № 3), pp. 439-477.

(2009): "La noción de incumplimiento esencial en el Código Civil", en: Revista de Derecho de la Pontificia Universidad Católica de Valparaíso (XXXII), pp. 221-258. 
WadDams, Stephen (2008): "Contract and Unjust Enrichement: competing categories or complementary concepts?, en: Essays for Peter Birks. Structure and Justification in Private Law (Oxford, Hart Publishing), pp. 167-183. 